\title{
Regulatory dissection of the CBX5 and hnRNPA1 bi-directional promoter in human breast cancer cells reveals novel transcript variants differentially associated with HP1a down-regulation in metastatic cells
}

\author{
Johan Vad-Nielsen ${ }^{1}$, Kristine Raaby Jakobsen ${ }^{1,2}$, Tina Fuglsang Daugaard ${ }^{1}$, Rune Thomsen ${ }^{1}$, Anja Brügmann ${ }^{3}$,
} Boe Sandahl Sørensen ${ }^{2}$ and Anders Lade Nielsen ${ }^{1 *}$

\begin{abstract}
Background: The three members of the human heterochromatin protein 1 (HP1) family of proteins, HP1a, HP1 $\beta$, and $\mathrm{HPY}$, are involved in chromatin packing and epigenetic gene regulation. HP1a is encoded from the CBX5 gene and is a suppressor of metastasis. CBX5 is down-regulated at the transcriptional and protein level in metastatic compared to non-metastatic breast cancer. CBX5 shares a bi-directional promoter structure with the hnRNPA1 gene. But whereas CBX5 expression is down-regulated in metastatic cells, hnRNAP1 expression is constant. Here, we address the regulation of CBX5 in human breast cancer.

Methods: Transient transfection and transposon mediated integration of dual-reporter mini-genes containing the bi-directional hnRNPA1 and CBX5 promoter was performed to investigate transcriptional regulation in breast cancer cell lines. Bioinformatics and functional analysis were performed to characterize transcriptional events specifically regulating CBX5 expression. TSA treatment and Chromatin Immunoprecipitation (ChIP) were performed to investigate the chromatin structure along CBX5 in breast cancer cells. Finally, expression of hnRNPA1 and CBX5 mRNA isoforms were measured by quantitative reverse transcriptase PCR (qRT-PCR) in breast cancer tissue samples.

Results: We demonstrate that an hnRNPA1 and CBX5 bi-directional core promoter fragment does not comprise intrinsic capacity for specific CBX5 down-regulation in metastatic cells. Characterization of transcriptional events in the $20 \mathrm{~kb}$ CBX5 intron 1 revealed existence of several novel CBX5 transcripts. Two of these encode consensus HP1a protein but used autonomous promoters in intron 1 by which HP1a expression could be de-coupled from the bidirectional promoter. In addition, another CBX5 transcriptional isoform, STET, was discovered. This transcript includes CBX5 exon 1 and part of intron 1 sequences but lacks inclusion of HP1a encoding exons. Inverse correlation between STET and HP1a coding CBX5 mRNA expression was observed in breast cancer cell lines and tissue samples from breast cancer patients.

Conclusion: We find that HP1a is down-regulated in a mechanism involving CBX5 promoter downstream sequences and that regulation through alternative polyadenylation and splicing generates a transcript, STET, with potential importance in carcinogenesis.
\end{abstract}

Keywords: Metastasis, Heterochromatin, Cell invasion, Epigenetics, Transcriptional regulation

\footnotetext{
* Correspondence: aln@biomed.au.dk

${ }^{1}$ Department of Biomedicine, The Bartholin building, Aarhus University,

DK-8000 Aarhus C, Denmark

Full list of author information is available at the end of the article
} 


\section{Background}

The heterochromatin protein 1 (HP1) family was first identified in Drosophila melanogaster as essential components of pericentric heterochromatin and shown to be implicated in chromatin compaction and epigenetic repression of gene expression [1]. In mammalian cells, the HP1 family is composed of three distinct genes: $C B X 5$, $C B X 1$, and $C B X 3$ encoding the highly conserved proteins: $\mathrm{HP} 1 \alpha, \mathrm{HP} 1 \beta$, and HP1 $\gamma$ [2-5]. The HP1 proteins consist of an N-terminal chromo domain (CD) and a structurally similar C-terminal chromo shadow domain (CSD) separated by a flexible hinge domain [6, 7]. The HP1 proteins have distinct chromatin distributions with HP1 $\alpha$ present mainly in heterochromatin, HP1 $\beta$ in both hetero- and euchromatin, and HP1 $\gamma$ primarily located in euchromatin [5, 8, 9]. Tethering HP1 proteins to chromatin through the $\mathrm{CD}, \mathrm{CSD}$ or heterologous DNA-binding domains results in transcriptional repression in cis $[8,10]$. The CD mediates HP1 binding to chromatin through specific interactions with di- and tri-methylated lysine 9 on the $\mathrm{H} 3$ histone tail (H3K9me2/3). Furthermore, the affinity for $\mathrm{CD}$ binding increases proportionally with the degree of methylation $[8,11,12]$. The CD also interacts with the tail of linker histone H1.4 methylated on lysine 26 which participates in further chromatin compaction [13]. The CSD functions as a HP1 protein-protein dimerization domain forming homo- and hetero-dimers [8, 14, 15]. The CSD dimeric structure is also an interaction platform for additional proteins through the core amino acid sequence PXVXL (X = any amino acid) [14, 15]. Many different types of proteins containing PXVXL motifs have been shown to interact with HP1 proteins through the CSD $[4,5,16-20]$. However, there are proteins that associate with the CSD of HP1 through alternative sequence motifs [10, 21, 22]. Notably, the CSD also interacts with the first helix of the histone fold of $\mathrm{H} 3$ to a PXVXL-like motif and this $\mathrm{H} 3$ region is involved in chromatin remodeling [23-26]. The hinge region of HP1 contributes to chromatin association through interactions with histone $\mathrm{H} 1$ and RNA. Through this interaction, RNA components are thought to be important in the maintenance and localization of HP1 proteins along specific sites at the genome, e.g. for $\mathrm{HP} 1 \alpha$ pericentric heterochromatin localization $[8,27-30]$. When HP1 is bound to di- or trimethylated $\mathrm{H} 3 \mathrm{~K} 9$ through the $\mathrm{CD}$, subsequent recruitment of SUV39h1 causes adjacent H3K9 residues to become methylated. This creates new binding sites for additional HP1 proteins, which, in turn, will further recruit SUV39h1 proteins. This mechanism explains how HP1 modulates the spread of heterochromatin into neighboring euchromatin, a phenomenon known as position effect variegation (PEV) [31-33]. PEV is suppressed with decreased HP1 expression and enhanced with increased HP1 expression [32, 33].
In breast cancer, the expression level of $C B X 5$ and encoded HP1 $\alpha$ correlates with both clinical outcome in terms of patient survival and clinical data in terms of tumor size and stage of this disease [34]. Tumor cells from primary breast carcinomas exhibit higher expression levels of HP1 $\alpha$ encoding mRNA and protein compared to normal breast tissue [34]. Moreover, $\mathrm{HP} 1 \alpha$ encoding mRNA and protein have also been shown to be down-regulated in highly invasive breast cancer cell lines (e.g. HS578T and MDA-MB-231) compared to poorly invasive breast cancer cell lines (e.g. T47D and MCF7) while HP1 $\beta$ and HP1 $\gamma$ were relative equally expressed [20, 35-37]. Immunohistochemical analysis of in vivo breast cancer samples showed that HP1 $\alpha$ expression was reduced in metastatic cells relative to the primary tumor corroborating the cell line findings [36]. Following RNAi-mediated knockdown of $\mathrm{HP} 1 \alpha$, poorly invasive MCF7 cells have increased invasive potential. Conversely, highly invasive MDA-MB-231 cells loose invasive potential following ectopic HP1 $\alpha$ expression $[36,38]$. Based on these data, $\mathrm{HP} 1 \alpha$ is defined as a metastasis suppressor, which in contrast to tumor suppressors is defined as factors being able to suppress metastasis without affecting the growth of the tumor [20, 36, 38, 39].

Analysis of the transcriptional regulation of $C B X 5$ in breast cancer cells have been performed with a resulting mapping of cis-elements and trans-factors [40, 41]. $C B X 5$ is orientated in a "head-to-head" bi-directional arrangement with hnRNPA1. The hnRNPA1 encoded protein belongs to the $\mathrm{A} / \mathrm{B}$ subfamily of heterogeneous nuclear ribonucleoproteins involved in the packaging of pre-mRNA into hnRNP particles, transport of poly adenylated mRNA from the nucleus to the cytoplasm, and may modulate splice site selection [42]. CBX5 and hnRNPA1 shares a $0.6 \mathrm{~kb}$ promoter sequence including binding sites for E2F and MYC-family transcription factors. Introduction of mutation in a USF/C-MYC recognition site upstream for the $C B X 5$ transcriptional start site diminished differential expression in invasive versus poorly invasive breast cancer cells [40]. Also, CBX5 promoter binding of the transcription factor YY1 is involved in regulating the differential expression levels in breast cancer cells [41]. The decrease in $C B X 5$ expression level in metastatic breast cancer cells correlates with decreased presence of H3K36me3, RNA polymerase II (Pol-II), and basal transcription factors at the promoter [37].

In this study, we find the differential expression of $C B X 5$ in metastatic versus non-metastatic breast cancer cells requires a decoupling from the bi-directional promoter architecture of $C B X 5$ and $h n R N P A 1$, and investigate sequences downstream of the $C B X 5$ promoter as possible mediators hereof. 


\section{Methods}

\section{Cell lines}

MCF-7 (non-invasive breast cancer cells), MDA-MB-231

(highly invasive breast cancer cells), HEMC (Primary human mammary epithelial cells) and HeLa (cervical cancer cells) were grown in Dulbecco's Modified Eagle's Medium DMEM (Lonza) supplemented with $10 \%$ fetal bovine serum, $1 \%$ penicillin and $1 \%$ glutamine. The cells were kept in a $\mathrm{CO}_{2}$-incubator with $5 \% \mathrm{CO}_{2}$ at $37{ }^{\circ} \mathrm{C}$. The MCF7 and MDA-MB-231 cell lines were purchased from American Type Culture Collection, USA and HEMC from Life Technologies. For TSA treatment of cells $3 \times 10^{5}$ MCF7 and MDA-MB-231 cells were seeded in 6 - well plates the day before treatment. At the day of treatment, the media was replaced with growth media containing $1 \mu \mathrm{M}$ TSA (Sigma) from a stock of $1 \mathrm{mM}$ dissolved in a DMSO solution of 1:3.3. As a control, separate cells where given growth media containing the same amount of DMSO. The cells were harvested after 24 hours. mRNA stability in the MDA-MB-231 and MCF7 cells lines was examined by treating cells with Actinomycin D (Sigma), which inhibits de novo Pol-II transcription. 24 hours prior to treatment, $5 \times 10^{5}$ cells were seeded in $25 \mathrm{~cm}^{2}$ flasks to reach a confluence of $80 \%$ at the time of treatment. Cells were added fresh DMEM growth media with Actinomycin D diluted in DMSO (1:3) to a final concentration of $10 \mu \mathrm{g} / \mathrm{ml}$. Cells from one $25 \mathrm{~cm}^{2}$ flask were harvested after $0,2,4,8,12$ and 24 hours, by washing twice with PBS and scraping in $1 \mathrm{ml}$ Tri Reagent ${ }^{\mathrm{Tm}}$ (Sigma) and subjected to RNA purification.

\section{Breast cancer tissue}

Breast tissue specimens were obtained from primary breast cancer surgical procedures as described [43]. The Regional Ethics Committee Northern Jutland, Denmark approved the study (N-20070047), and signed informed consent was obtained from each patient.

\section{RNA and CDNA}

RNA purification was performed using Tri Reagent ${ }^{\mathrm{TM}}$ (Sigma). The suspension was transferred to RNAse-free eppendorf tubes and incubated for 5 minutes. $200 \mu \mathrm{l}$ chloroform (Merck) was added per ml Tri Reagent and incubated for 10 minutes. After centrifugation at $12,000 x g$ for 15 minutes at $4{ }^{\circ} \mathrm{C}$, the upper RNAcontaining phase was transferred to RNAse-free eppendorf tubes. $500 \mu \mathrm{l}$ isopropanol (Merck) and $2 \mu$ l glycogen (Sigma) was added followed by centrifugation at $12,000 x g$ for 30 minutes at $4{ }^{\circ} \mathrm{C}$. The pellet was washed in $75 \%$ RNAse-free ethanol and dissolved in $50 \mu \mathrm{l}$ DEPC $\mathrm{H}_{2} \mathrm{O}$ and stored at $-20{ }^{\circ} \mathrm{C}$. RNA concentration was measured using a Thermo Scientific Nanodrop ${ }^{\text {тм }}$ spectrophotometer. RNA integrity was confirmed by running samples on $1 \%$ agarose gels with added ethidium bromide (AppliChem). For cell lines cDNA was synthesized from $0.5 \mu \mathrm{g}$ RNA using the BIO-RAD iScript $^{\mathrm{TM}}$ cDNA Synthesis kit containing a mix of oligo(dT) and random hexamer primers was used. After synthesis the cDNA product was diluted with redistilled water to a total volume of $100 \mu \mathrm{l}$ and stored at $-20{ }^{\circ} \mathrm{C}$. For breast cancer samples, cDNA was synthesized from RNA previously isolated from primary normal breast tissue, breast carcinomas and lymph node metastases $[43,44]$. cDNA was synthesized in a $20 \mu$ l reaction mix including $50 \mu \mathrm{mol} / \mathrm{L}$ Oligo(dT), reverse transcriptase (50 units $/ \mu \mathrm{L}$ ), RNase inhibitors ( 20 units $/ \mu \mathrm{L}$ ), $0.4 \mathrm{mmol} / \mathrm{L}$ of each dNTP, 1xPCR buffer, and $25 \mathrm{mmol} / \mathrm{L}$ MgCL2 (all from Applied Biosystems Inc., CA, USA). Reverse transcription was performed on the Perkin-Elmer GeneAmp PCR System 9600 Thermal Cycler (PerkinElmer Inc., MA, USA) with the profile: $42^{\circ} \mathrm{C}$ for 30 minutes, $99^{\circ} \mathrm{C}$ for 5 minutes and $4{ }^{\circ} \mathrm{C}$ until samples had cooled. cDNA was stored at $-20^{\circ} \mathrm{C}$ until further use.

For rapid amplification of cDNA $3^{\prime}$-ends (3'RACE) the first synthesis reaction utilized an oligo $(\mathrm{dT}) \mathrm{V}$ primer with anchor sequence (GCGGAATTCGGATCCCTCGAGTTTTTTTTTTTTTTTTTTTV*, "V denotes G, C or A). cDNA was synthesized using $2 \mu \mathrm{g}$ total RNA, $1 \mu \mathrm{l}$ oligo(dT)V primer (50 pmol), $1 \mu \mathrm{l}$ dNTP mix $10 \mathrm{mM}$ (Qiagen), and nuclease-free water to a final volume of $13 \mu \mathrm{l}$. After incubation at $65{ }^{\circ} \mathrm{C}$ for 5 minutes, $4 \mu$ l First Strand Buffer (Invitrogen) and $2 \mu \mathrm{l}$ DTT (Invitrogen) was added. Following incubation at $42{ }^{\circ} \mathrm{C}$ for 2 minutes, samples were added $1 \mu \mathrm{l}(15 \mathrm{U})$ Superscript II Reverse Transcriptase (Invitrogen) to a total volume of $20 \mu \mathrm{l}$ and further incubated at $42{ }^{\circ} \mathrm{C}$ for 50 minutes. The PCR reaction was conducted with $5 \mu \mathrm{l}$ of synthesized cDNA template, 10 pmol of target cDNA forward primer (CBX5 exon1 forward, GCAGACGTTAGCGTGAGTG) and 10 pmol of reverse oligo(dT)-r primer (GCGG AATTCGGATCCCTCGAGTT). A nested PCR was performed using reverse oligo(dT)-r primer and a target cDNA forward primer located downstream of the forward primer (STET nested forward, TGTAAGCC ACTCGAAGCCACA). PCR products of interest were extracted after gel electrophoresis and sequenced.

\section{Quantitative reverse transcriptase polymerase chain reaction (RT-qPCR)}

For cell lines, RT-qPCR was performed in a total reaction volume of $10 \mu \mathrm{l}$ including $1 \mu \mathrm{l} \mathrm{cDNA}, 5 \mu \mathrm{l}$ Roche LightCycler $^{\oplus} 480$ SYBR Green I Master enzyme (Roche), 10 pmol of both forward and reverse primer and double distilled water up to $10 \mu \mathrm{l}$. A LightCycler 480 (Roche) was used with a PCR profile of $10 \mathrm{sec}$ denaturation at $95{ }^{\circ} \mathrm{C}, 20 \mathrm{sec}$ annealing at $95^{\circ} \mathrm{C}$ and 1 min elongation at $72{ }^{\circ} \mathrm{C}$ for 50 cycles. A list of primers used in the study is given in Additional file 1: Table S1. All primers were 
checked for amplification efficiency to be above $90 \%$. Amplification efficiencies were calculated using data collected from a relative standard curve, constructed by performing serial dilutions of cDNA or purified PCR product. The relative mRNA expression was calculated using the $\mathrm{X}_{0}$-method, and normalized to the reference gene GAPDH [45]. For breast cancer samples, $H M B S$ was used to control for variations in RNA concentration and integrity and was found to be the best suited reference gene when compared to ACTB, GAPDH, YWHAZ and $B 2 M$ according to the Normfinder method [46]. Quantitative real-time PCR was performed using Roche LightCycler ${ }^{\circledR} 480$ with the settings stated above. The reaction mix consisted of $5 \mu \mathrm{L}$ SYBR Green I Master Mix Buffer (Roche), 2.5 pmol forward and reverse primers (Eurofins MWG Synthesis GmbH), $1 \mu \mathrm{L}$ cDNA and H20 to a final volume of $10 \mu \mathrm{L}$. The concentration was calculated using the standard curve method. Amplicon measurements outside of the range of the standard curve, or producing an incorrect melting peak were discarded.

\section{Morpholino and siRNA}

Morpholinos were designed by Gene Tools, LLC and transfected by the following procedure. 24 hours before transfection $5 \times 10^{4}$ MDA-MB-231 cells were seeded in 12 well plates. A transfection media of $1 \mathrm{ml}$ was prepared containing $6 \mu \mathrm{l}$ Endo-Porter $(6 \mu \mathrm{M}), 10 \mu \mathrm{l}$ Morpholinos $(10 \mu \mathrm{M})$ and $984 \mu \mathrm{l}$ DMEM growth media, added to the cells, and incubated in a $\mathrm{CO}_{2}$ incubator at $37{ }^{\circ} \mathrm{C}$ for 48 hours. The morpholinos had the following sequences: STET E2A1 ATCAGGAGAAAAAGATGA TTGCCCA, STET E2A2 GGACTCCTTCCTATTAGTA CAATGA, and Standard Control CCTCTTACCTCA GTTACAATTTATA. STET-targeting Morpholinos were pooled in equal amounts during preparation of transfection media. For siRNA Transfections, 100,000 MCF7 cells and 50,000 MDA-MB-231 cells were used per reaction. $20 \mu \mathrm{M}$ siRNA stocks kept at $-80{ }^{\circ} \mathrm{C}$ were diluted to $2 \mu \mathrm{M}$ with $1 \mathrm{x}$ Dharmacon buffer (Thermo Scientific). $25 \mu \mathrm{l}$ siRNA was added to $25 \mu \mathrm{l}$ DMEM (serum and penicillin/streptomycin free) and incubated for $5 \mathrm{mi}$ nutes. Transfection-mix was made by mixing $1 \mu \mathrm{l}$ Dharmafect 1 (Thermo Scientific) with $49 \mu \mathrm{l}$ DMEM (serum and penicillin free) per reaction and incubated for 5 minutes at room temperature. $50 \mu \mathrm{L}$ siRNA was added to $50 \mu \mathrm{l}$ transfection-mix and incubated for 20 minutes at room temperature before added to the cells following incubation in $\mathrm{CO}_{2}$ incubator for 72 hours. Transfections were made in duplicates for each siRNA. siRNA sequences were the following: RRP6, CCAGUUAUACAGACCUAU; and RRP40, CACGCACAGUACUAGGUC. As a negative control, Non-Targeting siRNA (Thermo Scientific, Cat. No. D001810-10-05) was used.

\section{Dual reporter mini-gene constructions, transfections and} genomic transpositions

Dual reporter mini-genes were constructed from the basis of the pVP4 vector, which includes a $C M V$ promoter driven expression cassette with the $\beta$-globin exon1-intron-exon2 fused to the EGFP encoding gene [47]. In addition, pVP4 includes an expression cassette for an autonomous neomycin resistance gene. By site directed mutagenesis, an $A s c I$ site was inserted central in the $\beta$-globin intron. By AseI and AscI digestion the entire $C M V$ promoter as well as the $\beta-$ globin exon1 and 5 'end of the intron was removed. A $1.1 \mathrm{~kb}$ PCR fragment representing the bi-directional hnRNPA1 and $C B X 5$ promoter with the exon1 sequences and approximately 200 bp intron 1 sequences was inserted. The promoter fragment was inserted in two different orientations using either primers Ase1-hnRNPA1, GATCATTAATGC AAGGAACGAAACCCAGCAGCATC, and Asc1-CBX5, GATCGGCGCGCCGTCCATTCATTTCACACAATAAC or Asc1-hnRNPA1, GATCGGCGCGCCGCAAGGAACG AAACCCAGCAGCATC, and Ase1-HP1 $\alpha$, GATCATT AATGTCCATTCATTTCACACAATAAC and thereby generating $\mathrm{p} C B X 5$-EGFP and phnRNPA1-EGFP. The vectors were cut by AseI and a PCR fragment inserted encompassing a $2 \mathrm{~kb}$ fragment with the 3 '-end of the $\beta$ globin intron, $\beta$-globin exon 2 , and the katushka reporter gene. This PCR fragment was generated with primers including NdeI sites, which are compatible with AseI. Thereby pBDf was generated that has the katushka transcriptional unit under control of the hnRNPA1 promoter and the EGFP transcriptional unit under control of the $C B X 5$ promoter. pBDr has the katushka transcriptional unit under control of the $C B X 5$ promoter and the EGFP transcriptional unit under control of the hnRNPA1 promoter. To generate a sleeping beauty transposon minigene, sbBDf, the required repetitive inverted elements were inserted to flank the katushka and EGFP transcriptional units in pBDf. A $2 \mathrm{~kb}$ fragment representing a continued extension of the $C B X 5$ intron 1 present in sbBDf was generated by PCR with primers $C B X 5$-Intron1Asc1-f, ACTGGGCGCGCCCGTTATTGTGTGAAATG AATG and CBX5-Intron1-Asc1-r, ACTGGGCGCGCCA CTCCCTAAACATTTCAAC and cloned in the AscI site to generate sbBDfPE. A $2 \mathrm{~kb}$ PCR fragment representing the STET exon including 3'-flanking intron sequences and $\mathrm{pA}$ signal downstream sequences was generated using the primers $S T E T$-Asc1-f,

TGACGGCGCGCCAGGTTTGGTATCAGGGTACA and STET-Asc1-r, TGACGGCGCGCCATAGCAGCC ACAGGAAACTA and cloned in the AscI sites of pBDf and sbBDf to generate pBDfS and sbBDfS, respectively. 24 hours before transfection $2 \times 10^{5}$ cells were seeded in a 6 well plate. Next day, $2 \mu \mathrm{g}$ of plasmid DNA, $6 \mu \mathrm{l}$ X-treme gene 9 (Roche) and serum 
free DMEM media was mixed in a volume of $200 \mu \mathrm{l}$ and incubated for 30 minutes at room temperature. The transfection mix was then added drop-wise to the growth media of the plated cells and incubated in $\mathrm{CO}_{2}$-incubator at $37{ }^{\circ} \mathrm{C}$ for 48 hours. For mini-gene genomic integration by transposition, $2 \times 10^{5}$ cells were seeded in a 6 well plate the day before transfection. Next day, $2 \mu \mathrm{g}$ of transposon mini-gene constructs, $200 \mathrm{ng}$ of SB Puro and $200 \mathrm{ng}$ of SB100 (10:1:1) were mixed with $7.2 \mu \mathrm{l}$ X-treme gene 9 and serum free DMEM media in a volume of $200 \mu \mathrm{l}$ and mixed thoroughly and incubated for 30 minutes at room temperature. The transfection mix was then added drop-wise to the growth media of the plated cells and incubated in $\mathrm{CO}_{2}$-incubator at $37{ }^{\circ} \mathrm{C}$ for 48 hours. The transfection media was replaced by selection media (DMEM supplemented with $1 \mu \mathrm{g} / \mathrm{ml}$ puromycin (Sigma)) to select for cells stably expressing the puromycin resistance gene. Every 2-3 days cells were washed twice with $1 \mathrm{ml}$ PBS and supplied with fresh selection media.

\section{Chromatin immunoprecipitation (ChIP)}

ChIP analyses were done essential as previously described $[37,48]$. In summary, ChIP was performed with $10 \mathrm{ml}$ cultures fixed with $1 \%$ formaldehyde for $10 \mathrm{~min}$ followed by addition of glycine to $0.25 \mathrm{mM}$ final concentration. Cross-linked cells were washed twice with cold PBS, scraped and lysed for $10 \mathrm{~min}$ at $4{ }^{\circ} \mathrm{C}$ in $1 \% \mathrm{SDS}$, $50 \mathrm{mM}$ Tris- $\mathrm{HCl}(\mathrm{pH} 8.0)$ and $10 \mathrm{mM}$ EDTA containing protease inhibitors. Lysates were sheared by sonication using a bioruptor (Diagenode, Liege, Belgium) to obtain chromatin fragments $<0.5 \mathrm{~kb}$ and centrifuged for $15 \mathrm{~min}$ in a microfuge at $4{ }^{\circ} \mathrm{C}$. $20 \mu \mathrm{g}$ of soluble chromatin of each sample was incubated with antibody to the following epitopes: H3 (ab1791, Abcam, MA, USA) and H3K9ac (ab4441, Abcam) at $4{ }^{\circ} \mathrm{C}$ for $18 \mathrm{~h}$ and immunoprecipitated with a protein $\mathrm{A}$ and protein $\mathrm{G}$ magnetic bead mix $(1: 1)$ at $4{ }^{\circ} \mathrm{C}$ for 60 min. A mock precipitation including pre-immune polyclonal serum was included for each ChIP experiment. After sequential washing by the following buffers: three times with ChIP washing buffer I (20 mM Tris-HCl, $150 \mathrm{mM} \mathrm{NaCl}, 2$ mM EDTA, $1 \%$ Triton X-100. $0.1 \%$ SDS), two times with ChIP washing buffer II $(20 \mathrm{mM}$ Tris- $\mathrm{HCl}, 350 \mathrm{mM} \mathrm{NaCl}$. 2 mM EDTA, 1 \% Triton X-100. $0.1 \%$ SDS), two times with ChIP washing buffer III (20 mM Tris- $\mathrm{HCl}$, $500 \mathrm{mM} \mathrm{NaCl} .2 \mathrm{mM}$ EDTA, $1 \%$ Triton X-100), the chromatin was eluted from the beads with Elution buffer (100 mM NaHCO3. $1 \%$ SDS) by rotating $15 \mathrm{~min}$ at room temperature. Cross-links were reversed by incubation at $65^{\circ} \mathrm{C}$ for 5 to $20 \mathrm{~h}$ and treated with proteinase $\mathrm{K}$ and RNase A. DNA was purified by phenol-chloroform extraction and ethanol precipitation and eluted in $100 \mu \mathrm{l}$
TE buffer. For quantitative detection of retained DNA, RT-qPCR were performed in triplicate and normalized to values obtained for amplicons corresponding to GAPDH.

\section{Western blot and immunofluorescence}

Proteins were detected in western blotting using mouse anti-HP1 $\alpha$ clone15.19 s2 (Millipore 05-689) in 1:1,000 dilution and rabbit anti- $\beta$-Actin (Sigma A2013) in 1:10,000 dilution. Secondary antibodies were goat antimouse-HRP (Dako P0447) and goat anti-rabbit-HRP (Dako P0448) in 1:10,000 dilutions. Western blot procedures using $75 \mu \mathrm{g}$ protein extract in each lane were as previously described except using Supersignal West Dure Extended Duration Substrate (Thermo Scientific 34076) and ImageQuant LAS4000 (GE Healthcare Life Sciences) for visualization [37]. For immunofluorescence experiments cells were grown in 12 well plates on coverslips (VWR) pre-coated with Poly-L-Lysine (Sigma) to a confluence of $\sim 60 \%$. Cells were crosslinked in $1 \mathrm{ml}$ PBS containing formaldehyde (final concentration of $1 \%$ ) for 10 minutes at room temperature. Crosslinking was quenched by adding $114 \mu \mathrm{l} 1.25 \mathrm{M}$ glycine mixing by gentle pipetting in the well and incubated further for 5 minutes at room temperature. Cells were washed twice with $1 \mathrm{ml}$ cold PBS and added $1 \mathrm{ml}$ PBS containing $0.5 \%$ Triton X-100 and protease inhibitors, and incubated for 15 minutes on ice. Cells were again washed twice with $1 \mathrm{ml}$ cold PBS and blocked by adding $1 \mathrm{ml}$ cold PBS containing $1 \%$ BSA (Sigma) and incubated for 1 hour on ice. Primary mouse anti-HP1 $\alpha$ antibody (1H5, Millipore) was diluted in PBS containing $1 \%$ BSA of which $40 \mu \mathrm{l}$ was placed on the bottom of a $10 \mathrm{~cm}^{2}$ petri-dish. The coverslips were placed on top of the $40 \mu \mathrm{l}$ antibody with the cell side downwards. The petri-dish was sealed and incubated on ice for 1 hour. Coverslips were transferred to a new 12 well plate containing $1 \mathrm{ml}$ cold PBS with the cell side upwards and washed $3 \times 5$ minutes on ice in $1 \mathrm{ml}$ cold PBS. Secondary antibodies (Invitrogen) were diluted 1:2000 in cold PBS containing $1 \% \mathrm{BSA}$, of which $1 \mathrm{ml}$ was added to the coverslips after removing the PBS. The plate was wrapped in tinfoil and incubated for 30-60 minutes on ice. Coverslips were washed $5 \times 5$ minutes in $1 \mathrm{ml}$ cold PBS and wrapped in tinfoil. Nuclei were dyed by adding $1 \mathrm{ml}$ DAPI (Sigma) and incubating for 2-5 minutes at room temperature, and washed twice in $1 \mathrm{ml}$ PBS. Coverslips were then dipped a few times in double distilled water and left to air dry in a tray wrapped in tinfoil. Coverslips were mounted on slides by adding a drop of Prolong Gold anti-fade reagent (Invitrogen) on the slide and transferring the coverslips on top with the cell side downwards. 


\section{Statistical analysis}

Statistical analyses were performed using the experimental results calculated by the $\mathrm{X} 0$-method from triple RTqPCR measurements for each sample [45] or the direct relative concentrations generated from the standard curves in the patient sample experiments. $P$-values were calculated using Students paired two-tailed t-test. Each experiment was repeated minimum three times.

\section{Results \\ HP1a down-regulation in MDA-MB-231 cells and the CBX5 and hnRNPA1 bi-directional transcriptional unit structure}

The expression of $C B X 5$ transcripts with coding potential for $H P 1 \alpha$ is decreased in invasive and migratory MDA-MB-231 breast cancer cells compared to the poorly invasive and migratory MCF-7 breast cancer cells $[20,36,38,40]$. The decrease in HP1 $\alpha$ expression is functionally linked to the enhanced invasion and migration capacity of MDA-MB-231 cells [36, 38, 40]. CBX5 has a bi-directional promoter arrangement with hnRNAP1 (Fig. 1a). In contrast to CBX5, hnRNPA1 is relative equally expressed in MDA-MB-231 and MCF7 cells (Fig. 1, Additional file 2: Table S2 and [37]). Thus, expression regulation of cellular amounts of HP1 $\alpha$ must mechanistically be possible without associated alterations in the housekeeping gene $h n R N P A 1$. We note that previous analyses of HP1 $\alpha$ coding mRNA regulation have been focused on the $C B X 5$ promoter sequences. However, due to the close proximity, it must be taken into account that an element affecting the transcriptional activity of $C B X 5$ could also affect the activity of $h n R N P A 1$. Despite the bi-directional promoter structure, no overall significant correlation in expression pattern is observed between CBX5 and hnRNPA1 in the NCI-60 cancer cell line panel (correlation coefficient 0.129) (Fig. $1 \mathrm{~b}$ and Additional file 3: Figure S1). To investigate the relation between $C B X 5$ and $h n R N P A 1$ expression, RT-qPCR analysis in HMEC, MCF7 and MDA-MB-231 cells was performed. This showed 2.9-fold up-regulation of $C B X 5$ relative to $h n R N P A 1$ in MCF7 cells versus noncancer breast epithelial cells (HMEC) and 0.62-fold down-regulation in MDA-MB-231 cells relative to HMEC (Fig. 1c). The expression analyses supported existence of independent regulation of $C B X 5$ and hnRNPA1 transcription in breast cancer cells with a concordant up-regulation of the two genes from normal cells to cancer cells and subsequently specific downregulation of $C B X 5$ in metastatic cells (Fig. 1c). In a previous study, we showed that the $C B X 5$ promoter is less occupied by basal transcription factors such as TBP, TFIIB, TFIIH as well as Pol-II in MDA-MB-231 cells when compared to MCF7 cells [37]. The decrease in Pol-II presence was over the entire CBX5 gene. In contrast, histone $\mathrm{H} 3$ and the promoter signature marks, tri-methylated lysine 4 (H3K4me3) and acetylated lysine 9 (H3K9ac) on the histone tail of $\mathrm{H} 3$, were equally present throughout the promoter [37]. Thus, we hypothesized two models facilitating differential regulation of $C B X 5$ and $h n R N P A 1$ from the basis of a bi-directional promoter. Either cis-binding of trans-regulators mediates specific regulation in the $C B X 5$ transcriptional orientation or presence of regulatory elements outside the bidirectional promoter region that control transcription specifically in the $C B X 5$ orientation. To test this, we constructed dual reporter mini-genes wherein the $C B X 5$ and hnRNPA1 bi-directional promoter including both first exons and flanking intron sequences drives bidirectional expression of either green (EGFP) or red (Katushka) fluorescent proteins (Fig. 1d). After transient transfection into MCF7 and MDA-MB-231 cells, we observed no preferential down-regulation of $C B X 5$ in MDA-MB-231 cells compared to MCF7 cells (Fig. 1d). Flipping the promoter region relative to the marker genes provided similar results (Fig. 1d). Thus, we conclude that the bi-directional promoter region per se is not sufficient to mediate preferential $C B X 5$ downregulation compared to $h n R N P A 1$ in MDA-MB-231 cells versus MCF7 cells.

The transient transfection approach most likely eliminates detection of putative chromatin mediated effects and can be affected by high promoter sequence copynumber mediated titration of trans-factors. To reduce such confounders, we constructed a sleeping beauty based transposon mini-gene with the CBX5 and hnRNPA1 bi-directional promoter (Fig. 1e). The minigene was used to generate stable genome insertion with sleeping beauty transposase in MCF7 and MDA-MB-231 cells. Pools of cells with genome insertions were examined for transcriptional orientation specific mRNA expression. The result again showed that the bi-directional promoter does not have intrinsic capacity to preferential mediate $C B X 5$ relative to $h n R N P A 1$ transcriptional down-regulation in MDA-MB-231 cells versus MCF7 cells (Fig. 1e). The mini-gene lacked complete inclusion of the two CpG islands overlapping the bi-directional promoter and we therefore generated a mini-gene with a $2 \mathrm{~kb}$ intron 1 extension (Fig. 1a and e). Similar to the $C B X 5$ and bi-directional promoter structure, $C B X 3$ and hnRNPA2B1 have a $0.4 \mathrm{~kb}$ bi-directional promoter region, suggesting an evolutionary relationship between the HP1 encoding genes (Additional file 3: Figure S1C). The $C B X 3$ and hnRNPA2B1 bi-directional transcriptional unit has been carefully analyzed due to the insulator capacity towards heterochromatin mediated gene silencing in transgenic constructs by the bi-directional promoter overlapping A2UCOE CpG island [49]. We note that the $\mathrm{CpG}$ containing fragment from the $C B X 5$ 


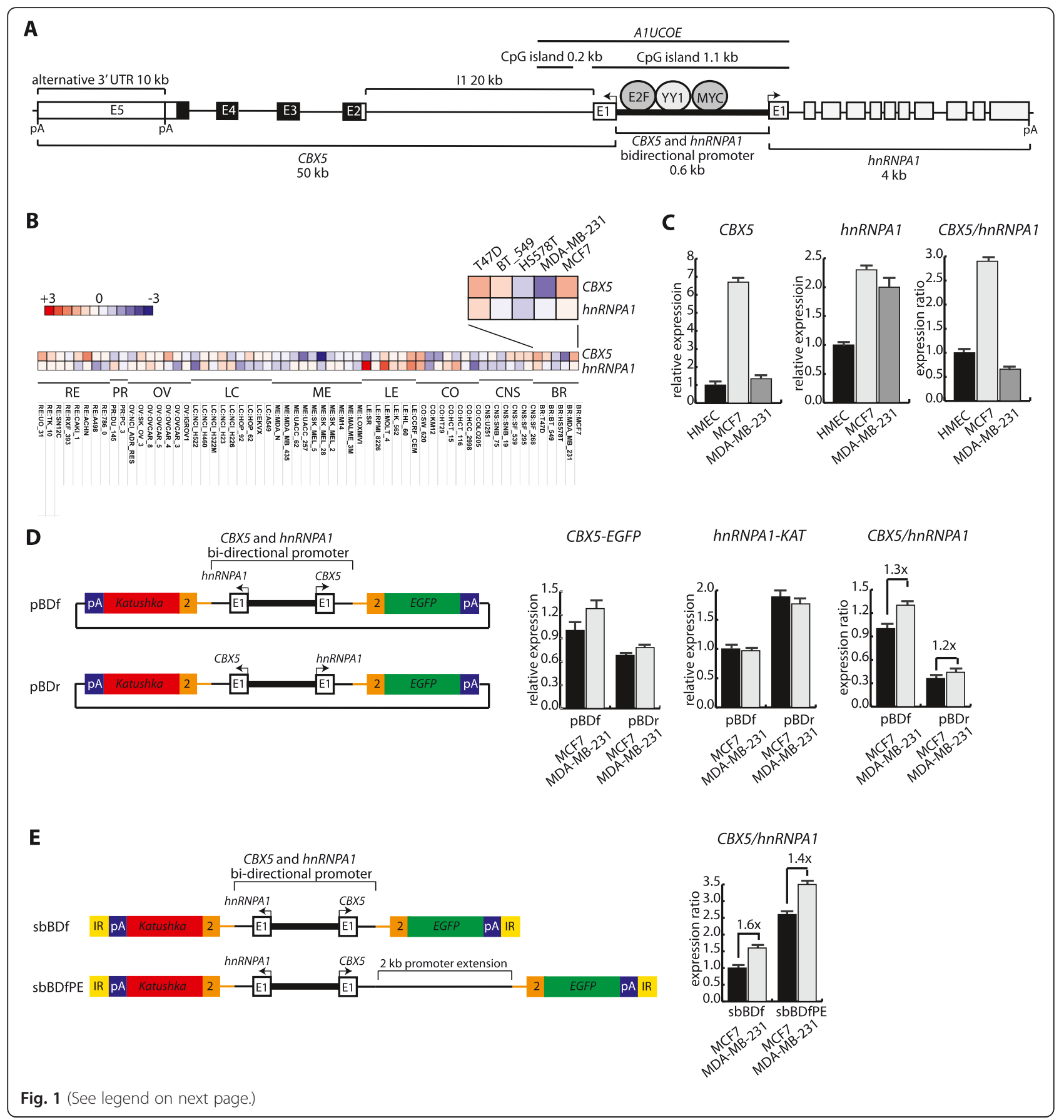


(See figure on previous page.)

Fig. 1 hnRNPA1 and CBX5 bi-directional promoter activity in breast cancer cells. a Schematized view of the CBX5 and hnRNPA1 genes (not drawn to scale). Arrows indicate direction of transcription. Localizations of transcription factor binding motifs in the bi-directional promoter were obtained from [37, 40,41]. The HP1 a coding region is indicated by black colouring. PA indicates the localization of poly-A signals. A1UCOE represents a $\mathrm{CpG}$ rich region homologous in localization to the characterized insulator element A2UCOE from the hnRNPA2B1 and CBX3 bi-directional promoter. $\mathbf{b}$ Correlation analysis of CBX5 and hnRNPA1 expression in the NCl-60 breast cancer cell panel. The analysis presented as heat map was performed using the CellMiner database, http://discover.nci.nih.gov/cellminer/, with red symbolizing positive and blue negative correlation. c Expression analysis of CBX5 and hnRNPA1 in HMEC, MCF7, and MDA-MB-231 cells. Relative expression was calculated from RT-qPCR using GAPDH expression for normalization. CBX5 primers located to exon 4 and 5 and hnRNPA1 primers to exon 1 and 2. d Transient transfection analysis of CBX5 and hnRNPA1 bi-directional promoter activity in dual reporter minigenes in MCF7 and MDA-MB-231 cells. $48 \mathrm{~h}$ after transfection RT-qPCR was used to detect relative expression levels of the spliced minigene derived reporter fusion transcripts. Expression of the vector co-expressed neomycin marker was used for normalization for transfection efficiency. Fold changes in expression ratio are shown in the right section. e Genomic transposition analysis of the CBX5 and hnRNPA1 bi-directional promoter activity in dual reporter minigenes in MCF7 and MDA-MB-231 cells. Stable cell lines generated by sleeping-beauty transposition of minigenes were analyzed by RT-qPCR to determine the expression levels of the spliced minigene derived reporter fusion transcripts. Because of copy integration number differences per transposition only the ratio of expression which was copy number independent is displayed. Fold changes in expression ratio are shown. For all panels, bars represent mean values with standard deviations

promoter resembles the $A 2 U C O E$ from $C B X 3$ and hnRNPA2B1, and we abbreviate the corresponding sequence $A 1 U C O E$. The inclusion of $A 1 U C O E$ had a similar positive effect on $h n R N P A 1$ and $C B X 5$ transcriptional orientations (Fig. 1e). Based on the presented expression analyses, we conclude that the observed specific downregulation of the $C B X 5$ transcriptional orientation in MDA-MB-231 breast cancer cells, and thereby HP1 $\alpha$ protein, most likely is not strictly promoter dependent, but involves promoter downstream sequences.

\section{Deciphering novel transcripts originating from the large intron 1 of $\mathrm{CBX} 5$}

Inspection of $C B X 5$ revealed existence of a large intron 1 sequence of approximately $20 \mathrm{~kb}$ (Fig. 1a). Intron $1 \mathrm{se}-$ quences are approximately $23 \mathrm{~kb}$ and $1 \mathrm{~kb}$ for $C B X 1$ and $C B X 3$ (Additional file 3: Figure S1). In an attempt to address the importance of the intron 1 sequence for $C B X 5$ regulation, we checked for the presence of transcriptional signatures using ENCODE data in the UCSC browser. We note that human $C B X 1$ and $C B X 3$ genes have alternative exon 1 sequences, and thereby alternative promoters (Additional file 3: Figure S1). From ENCODE derived data, two CBX5 signatures were evident. One representing possible additional promoter sequences in the 3 -region of intron 1 and another indicating the presence of a splice form between $C B X 5$ exon 1 and an intron 1 embedded alternatively used exon (Fig. 2a). The latter will be described in further details below, and we will here focus on the putative alternative promoters in intron 1. Due to the existing nomenclature in UCSC of various transcriptional isoforms from $C B X 5$, we will in the following term the HP1 $\alpha$ protein-coding mRNA isoform originating from the CBX5 and hnRNPA1 bi-directional promoter for $H P 1 \alpha$-Variant 3 $(V 3)$. The two novel potential mRNA isoforms are termed HP1 $\alpha$-Variant 1 (V1) and HP1 $\alpha$-Variant $2(V 2)$ with the latter having the most $5^{\prime}$-intron 1 location of the alternative exon 1 (Fig. 2a). The ENCODE data showed peaks of promoter mark signatures, H3K27ac and H3K4me3, as well as the presence of Pol-II over the alternative exon 1 sequences for $H P 1 \alpha-V 1$ and $H P 1 \alpha-V 2$ (Fig. 2a). This is in support of the presence of functional promoter sequences. We note that $H P 1 \alpha-V 1, H P 1 \alpha-V 2$, and $H P 1 \alpha-V 3$ mRNA isoforms all have coding potential for full-length HP1 $\alpha$ protein given that the first consensus translational initiation codon resides in exon 2 for all three transcripts (Fig. 2a). The novel HP1 $\alpha$ encoding transcriptional isoforms, $V 1$ and $V 2$, could participate in generating relatively higher $\mathrm{HP} 1 \alpha$ expression in nonmetastatic MCF7 breast cancer cells without requirement of specific CBX5 to hnRNPA1 transcriptional enhancement from the bi-directional promoter. To address this, we performed RT-qPCR analysis specifically detecting each transcriptional isoform in HMEC, MCF7 and MDA-MB-231 cells. We observed similar expression profiles for $H P 1 \alpha-V 1$ and $H P 1 \alpha-V 2 . H P 1 \alpha-V 3$ had a distinct expression profile, which was similar to HP1 $\alpha$ encoding mRNA detected by primers located in exons 4 and 5 and thereby the three isoforms altogether $(H P 1 \alpha-$ pan) (Fig. 2b). PCR experiments showed that the $H P 1 \alpha$ $V 3$ expression ratio relative to $H P 1 \alpha-V 1$ and $H P 1 \alpha-V 2$ was approximately 20-fold higher in HMEC, 3,500-fold higher in MCF7 and 30-fold higher in MDA-MB-231 cells (Fig. 2c). Thus, expression data did not support that $H P 1 \alpha-V 1$ and $H P 1 \alpha-V 2$ transcripts contribute significantly to the overall $\mathrm{HP} 1 \alpha$ encoding transcript levels in neither MCF7 nor MDA-MB-231 cells. ENCODE data showed the highest peak of Pol-II over the alternative promoter sequences in HeLa cells (Fig. 2a). By RTqPCR, we also found that HeLa cells express $H P 1 \alpha-V 1$ and $H P 1 \alpha-V 2$ at a level comparable to $H P 1 \alpha-V 3$ (Fig. $2 \mathrm{~b}$ and c). Thus, the HP1 $\alpha$ encoding $V 1$ and $V 2$ transcripts might in some cellular contexts quantitatively contribute 


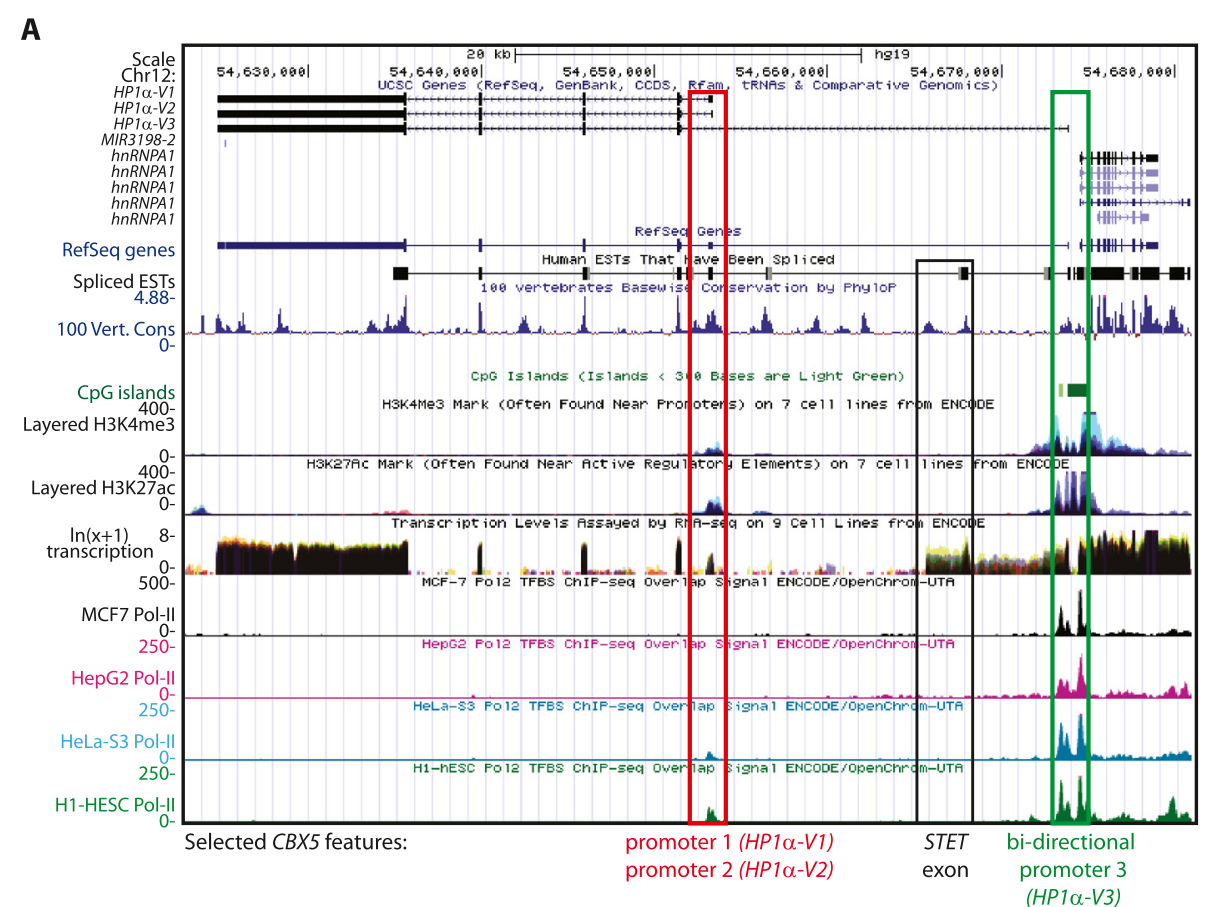

B

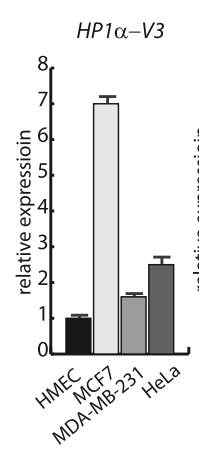

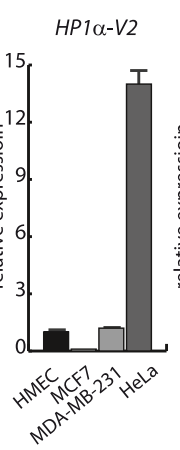

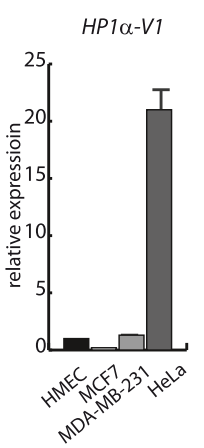

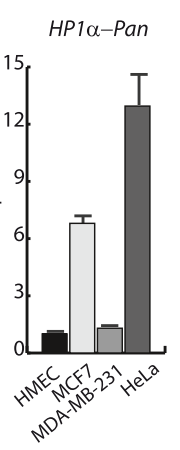

C

Fig. 2 Identification of novel CBX5 generated transcripts. a Screenshot from the UCSC Genome Browser showing selected features of CBX5 and hnRNPA1 from subtracted ENCODE datasets. On the $y$-axis is displayed the nature of described features. Layered H3K4me3 and H3K27ac represent ChIP-sequence results for 7 model cell lines from ENCODE. Transcription indicates the result of RNA sequencing from 9 model cell lines from ENCODE. MCF7, HePG2, HeLa-S3, and H1-HESC Pol-II indicates ChIP sequence results from the given cell lines. The numbering on the y-axix for each feature indicates the quantitative measure for the RNA and ChIP sequence results. By colored boxes and the below text is indicated the localization of the bi-directional promoter as well as intron 1 located examined alternative promoter and exon sequences. $\mathbf{b}$ Expression analysis of CBX5 derived transcripts and hnRNPA1 in HMEC, MCF7, MDA-MB-231, and HeLa cells. Relative expression was calculated from RT-qPCR using GAPDH expression for normalization. CBX5 transcript primers were specific for the indicated isoforms and HP1a-pan was detected by an exon 4 and 5 primer combination. $\mathbf{c}$ Expression ratio of HP1a encoding transcripts. The ratio between HP1a-V3 in relation to the sum of HP1a-V1 and HP1a-V2 was calculated based on the data in B. For all panels, bars represent mean values with standard deviations

to the total HP1 $\alpha$ encoding transcript levels. In conclusion, the analysis of the novel $H P 1 \alpha-V 1$ and $H P 1 \alpha-V 2$ transcript isoforms were not supportive for a role directly involved in $\mathrm{HP} 1 \alpha$ transcript and protein downregulation in MDA-MB-231 compared to MCF7 cells.

We have previously shown that the $\mathrm{H} 3$ content over CBX5 is equal in MCF7 and MDA-MB-231 cells, whereas the chromatin mark coupled with transcriptional elongation, H3K36me3, was decreased over the $C B X 5$ gene body in MDA-MB-231 cells compared to MCF7 cells [37]. Chromatin compaction in $C B X 5$ intron 1 could contribute to the low expression of $H P 1 \alpha-V 1$ and $H P 1 \alpha-V 2$. To address chromatin-mediated regulation, we treated MCF7 and MDA-MB-231 cells with the histone deacetylase inhibitor trichostatin-A (TSA). Previous results have shown equal amounts of $\mathrm{H} 3 \mathrm{~K} 9 \mathrm{ac}$ at the $C B X 5$ 
promoter in MCF7 and MDA-MB-231 cells [37]. To our surprise, we observed that in MDA-MB-231 cells TSA treatment resulted in 5-fold decreased CBX5 expression for all three HP1 $\alpha$ encoding transcript isoforms (Fig. 3a). In MCF7, no significant TSA effect was observed (Fig. 3a). $h n R N P A 1$ expression was 2 -fold decreased following TSA treatment and this was also observed in MCF7 cells (Fig. 3a). We also observed HP1 $\alpha$ protein down-regulation by western blotting and immunofluorescence analysis (Fig. 3b and Additional file 4: Figure S2B and S2C). ChIP analysis showed that the H3K9ac/H3 ratio in MDA-MB231 cells decreased or was equal at the $C B X 5$ and hnRNPA1 bi-directional promoter and increased at $C B X 5$ downstream sequences following TSA treatment (Fig. 3c). Notably, the ChIP results for the alternative promoter regions for $H P 1 \alpha-V 1$ and $H P 1 \alpha-V 2$ showed a 3 -fold increased level of H3K9ac, which did not correlate with increased mRNA expression (Fig. 3c).
Identifying a novel transcript isoform, STET, originating from alternative splicing and polyadenylation in intron 1 of CBX5

To further delineate the transcriptional structure of $C B X 5$ intron 1 we next focused on an embedded alternative exon indicated by transcriptional signatures using ENCODE data in the UCSC browser. In silico a CBX5 transcript was identified consisting of exon 1 fused to this alternative spliced and polyadenylated exon embedded in intron 1 (Figs. 2a and 4a). We abbreviated this transcript for $C B X 5$ skipped terminal exon transcript (STET). To verify the expression of STET, and eventual other $C B X 5$ intron 1 derived transcripts, we screened for RNA expression using RT-PCR amplicons representing different intron 1 positions (Fig. 4a). Relative to amplicon $A 4$ representing the intron 1 to STET1 exon boundary we observed an increase in RNA levels particularly in MDA-MB-231 cells corresponding to amplicon A5
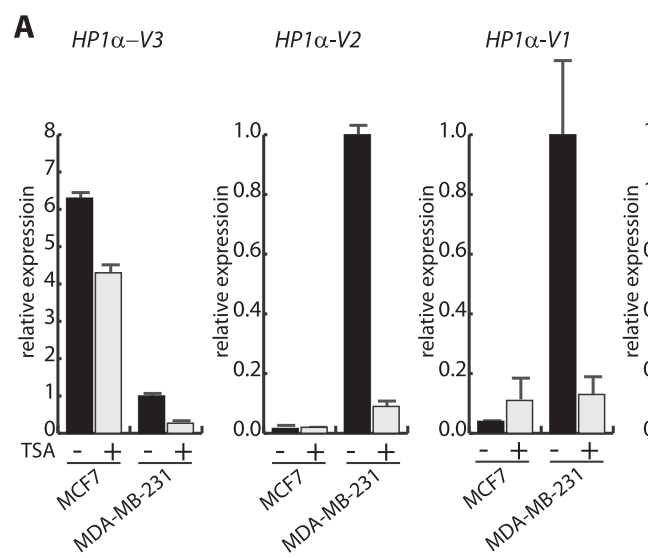

hnRNPA1

B

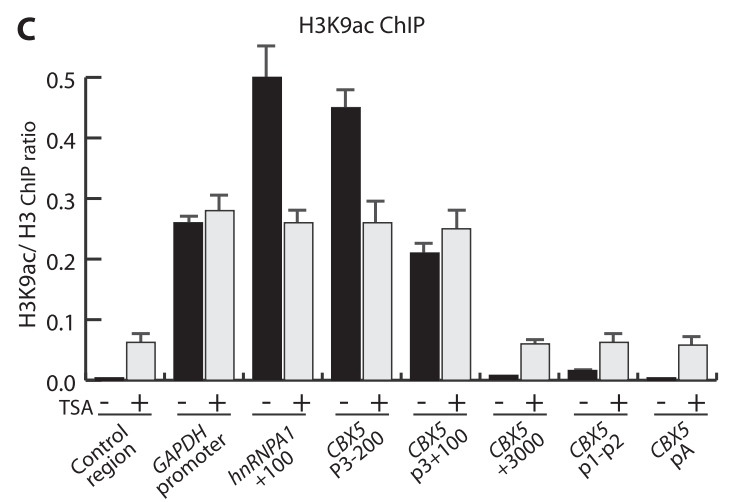

Fig. 3 TSA is a negative regulator of the CBX5 and hnRNPA1 locus. a TSA mediates CBX5 down-regulation. Relative expression of CBX5 derived transcripts and hnRNPA1 in MCF7 and MDA-MB-231 cells in a TSA response after $24 \mathrm{~h}$ treatment. Relative expression was calculated from RT-qPCR using GAPDH expression for normalization. CBX5 transcript primers were specific for the indicated isoforms and HP1a-pan was detected by an exon 4 and 5 primer combination. $\mathbf{b}$ TSA down-regulates HP1a expression at the protein level. Protein extracts were isolated from MCF7 and MDA-MB-231 cells in a TSA response after $24 \mathrm{~h}$ treatment. Western blot analyses were performed with antibodies for HP1a and $\beta$ - Actin for loading control using the same membrane. c H3-K9ac and H3 ChIP analysis of the CBX5-hnRNPA1 locus. ChIP analysis were performed from MDA-MB-231 control cells or treated with TSA for $24 \mathrm{~h}$. The presented data shows the H3K9ac signal relative to H3 signal. Positions of PCR primers are indicated. The control region is located in the un-transcribed genomic position. For all panels, bars represent mean values with standard deviations 

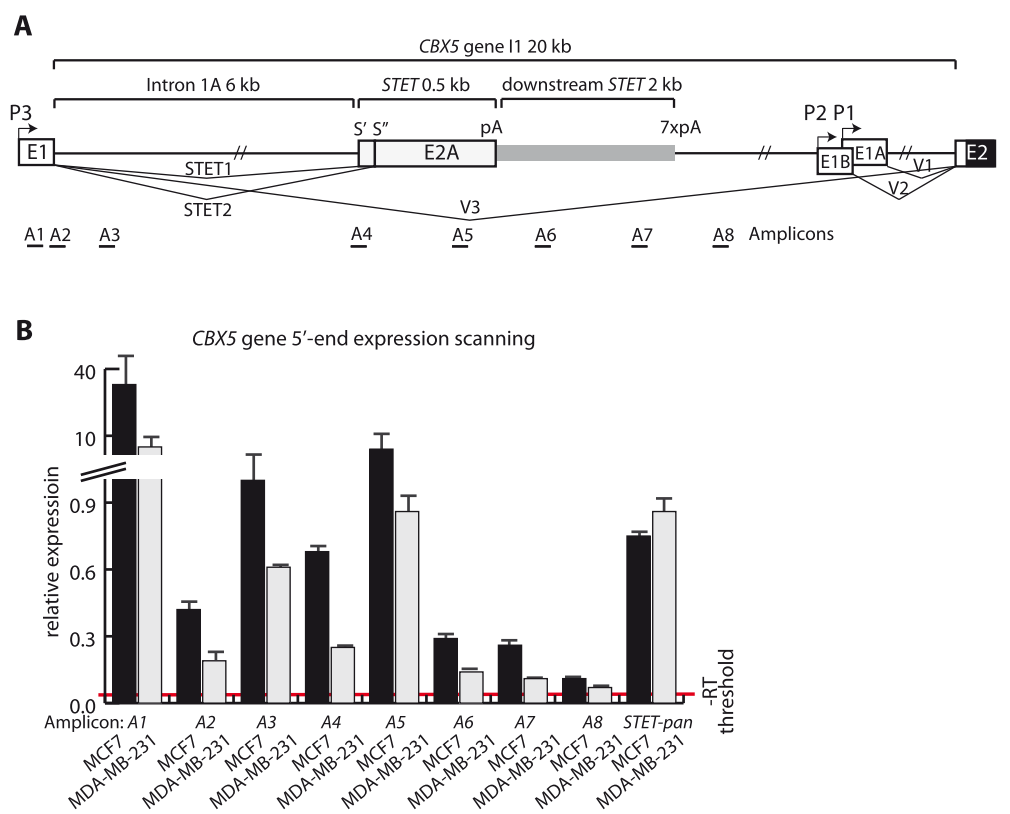

C

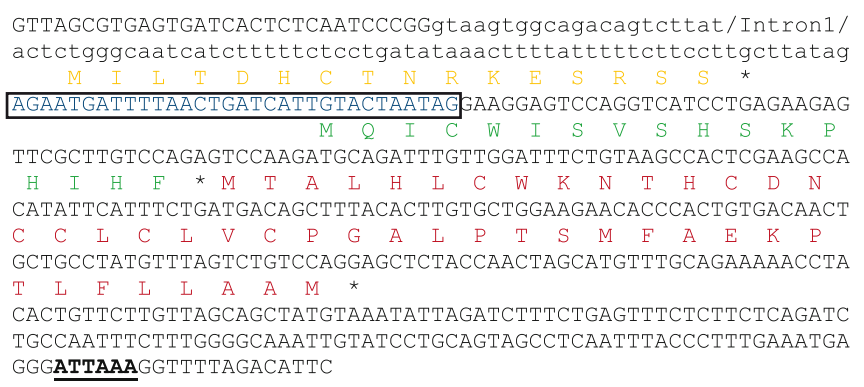

D

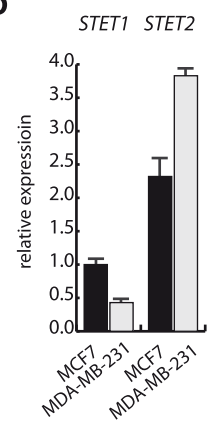

E

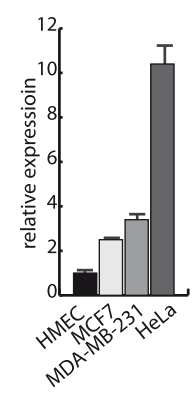

HP1 $\alpha-V 3$ / STET-pan

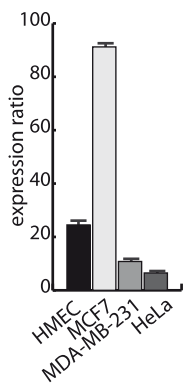

$\mathbf{F}$

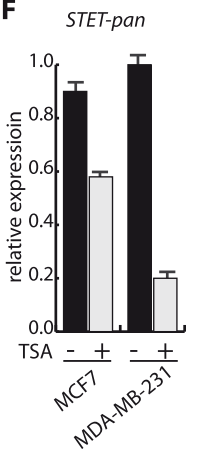

Fig. 4 (See legend on next page.) 


\begin{abstract}
(See figure on previous page.)
Fig. 4 CBX5 intron 1 generates a novel transcript STET. a Schematized view of CBX5 intron 1. Arrows indicate direction of transcription and rectangles indicate exon sequences. The HP1 a coding region is indicated by black colouring. PA indicates the localization of poly-A signals. E1 is the first exon for HP1a-V3, E1A is the first exon for HP1a-V1, E1B is the first exon for HP1a-V2, and E2A the terminal composite exon for the STET transcript. The two different STET transcripts, STET1 and STET2, using different splice sites are also indicated. Below the intron drawing is indicated location of amplicons used to detect transcription throughout the CBX5 intron 1. b Scanning of CBX5 intron 15 '-region for expressed transcripts. Primer localizations for the various amplicons is shown in A. STET-pan indicates the measurement of the spliced STET transcript. Relative expression was calculated from RT-qPCR using GAPDH expression for normalization. -RT threshold line in red shows the level of background calculated from paired samples with a cDNA syntheses reaction without reverse transcriptase to account for the detection of contaminating DNA. c Nucleotide sequence of the STET E2A and surrounding sequences. The exon sequence extension in STET1 is enclosed by rectangle. pA signal is underlined and in bold. Different ORF's are shown with the peptide sequences in color. $\mathbf{d}$ Expression analysis of STET transcripts in MCF7 and MDA-MB-231 cells. Relative expression was calculated from RT-qPCR using GAPDH expression for normalization. e Expression analysis of STET-pan in HMEC, MCF7, MDA-MB-231, and HeLa cells. Relative expression was calculated from RT-qPCR using GAPDH expression for normalization. The calculated semi-quantitative expression ratio between HP1a-V3 and STET is shown to the right. f TSA mediates STET transcript down-regulation. Relative expression of STET-pan mRNA in MCF7 and MDA-MB-231 cells after $24 \mathrm{~h}$ TSA or DMSO control treatment. Relative expression was calculated from RT-qPCR using GAPDH expression for normalization. For all panels, bars represent mean values with standard deviations
\end{abstract}

representing the STET 3'-UTR (Fig. 4b). Amplicons located further downstream in intron 1 showed pronounced decrease in RNA levels in accordance with a major transcriptional stop mediated by the STET pA signal (Fig. 4b). We notice the presence of an array of 7 consensus pA signals $2 \mathrm{~kb}$ downstream from the STET pA signal in the $C B X 5$ intron 1 sequence. Downstream of this multiple pA signal array, RNA transcript levels approached background (Fig. 4b). However, we could not identify transcripts terminated by the seven downstream pA signals by 3 '-RACE. We note that downstream AU-rich regions can be important contributors in co-transcriptional cleavage (CoTC). During CoTC cleavage of the nascent transcript occurs 1-2 kb downstream of the polyadenylation signaling event, thereby releasing the polymerase followed by a subsequent cleavage at the pA signal [50]. In conclusion, the expression data supported the existence of significant amounts of cellular RNA representing intron 1, including the STET exon (Fig. 4b). Further RT-PCR analyses and sequencing of amplicons verified the existence of STET mRNA in both MCF7 and MDA-MB-231 cells and that two different STET mRNAs were present (Fig. 4a-d). STET1 included an additional extension of 32 bases in the $5^{\prime}$-end compared to STET2 (Fig. 4a and c). 3'-RACE analyses showed that the STET isoforms were polyadenylated from an AUUAAA pA signal resulting in exon lengths of 383 and 351 bp for STET1 and STET2, respectively (Fig. 4c). Of additional sequence elements required for a functional pA signal, we note the presence of an upstream UGUA-element and downstream U-rich elements, which mediates binding of CstF-64 [51] surrounding the STET AUUAAA motif (Fig. 4c). BLAST searches identified significant STET evolutionary conservation in various primates, including existence of the two alternative splice forms of STET in e.g. marmoset, but absence of STET in rodents. PCR experiments showed that STET2 mRNA was more abundant than
STET1 mRNA in MCF7 and MDA-MB-231 cells (Fig. 4d). However, whereas STET1 was 0.43-fold downregulated in MDA-MB-231 compared to MCF7 cells, STET2 was 1.65 -fold up-regulated (Fig. 4d). Using a primer set detecting both STET mRNA isoforms, STETpan, we observed that $H P 1 \alpha-V 3$ down-regulation in MDA-MB-231 versus MCF7 cells was not linked to decreased STET expression supporting independent regulation of the transcript levels (Fig. 4e). In contrast, TSA treatment resulted in similar response profiles for STET and $H P 1 \alpha-V 3$ (Figs. $4 \mathrm{f}$ and $3 a$ ).

\section{Increased STET mRNA expression is not directly functionally associated with down-regulation of HP1a encoding mRNA}

Each coupled alternative splicing and pA event resulting in one STET mRNA could decrease the generation of one consensus $\mathrm{HP} 1 \alpha$ encoding transcript isoform $V 3$ through STET exon pA mediated transcriptional termination. In a straightforward hypothesis, the increased generation of STET mRNA could mediate HP1 $\alpha$ encoding mRNA down-regulation in metastatic breast cancer cells. In this case, the generation of STET transcripts would be at the same order of magnitude as HP1 $\alpha$ encoding transcripts and STET mRNA down-regulation would follow $H P 1 \alpha-V 3$ mRNA up-regulation and vice versa. Expression analysis, however, showed a $H P 1 \alpha-V 3$ relative to STET expression in the order of 90 -fold in MCF cells and 10-fold in MDA-MB-231 cells (Fig. 4e). $H P 1 \alpha-V 3$ mRNA is stable and low STET mRNA stability could lead to underestimation of the STET mRNA synthesis rate $[37,41]$. This was not the case as RNA stability analysis showed an approximately similar stability of STET mRNA and $H P 1 \alpha-V 3$ mRNA (Additional file 5: Figure S3A). Moreover, rapid degradation of nascent STET mRNA by the RNA exosome could decrease the steady-state levels. siRNA mediated depletion of essential exosome components RRP6 and RRP40 influenced 
$H P 1 \alpha-V 3$ mRNA and STET mRNA levels, but not in an order of magnitude to support this mechanism to be involved generating preferential low levels of STET mRNA (Additional file 5: Figure S3B and C).

We next examined if down-regulation of STET mRNA directly associated with $H P 1 \alpha-V 3$ mRNA up-regulation. For this, we examined the consequences of downregulating STET synthesis with morpholinos corresponding to the splice sites for the STET exon. Morpholino transfection of MDA-MB-231 cells with an equal mix of morpholinos targeting either of the splice sites resulted in 5-fold decrease in the amounts of spliced STET transcripts (Fig. 5a). This was not accompanied by a similar alteration in the amounts of un-spliced STET mRNA (amplicon A4) or RNA corresponding to the downstream utilized STET pA signal (amplicon A6) (Fig. 5a). A 0.63-fold decrease in

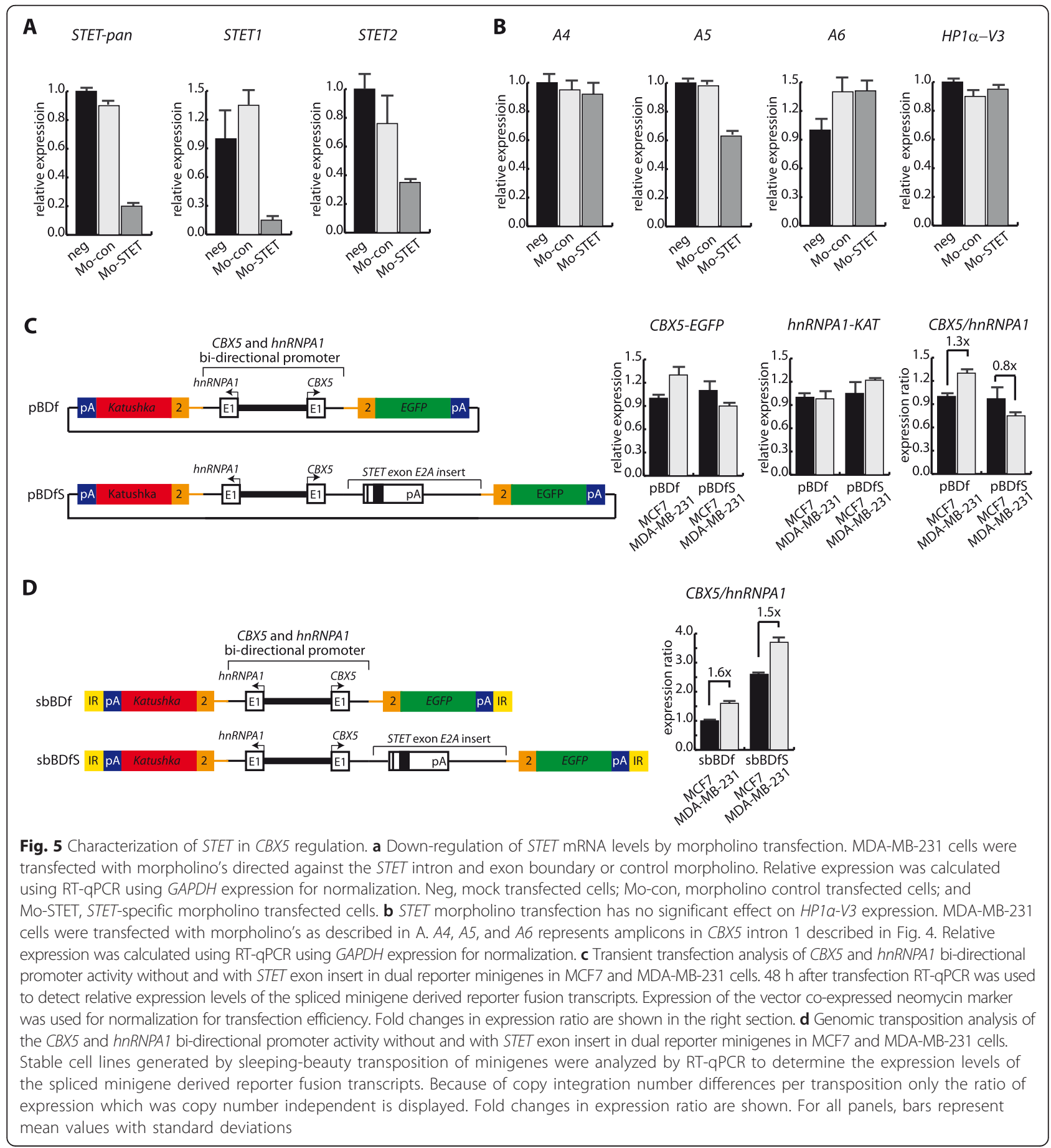


expression was observed using an amplicon detecting both spliced and un-spliced STET (amplicon A5) (Fig. 5b). This was in accordance with a linkage between blocking of STET mRNA splicing and blocking of STET pA signal usage altogether resulting in a decrease in total STET generation. No corresponding increase in $H P 1 \alpha-V 3$ mRNA expression was observed un-favouring that STET mRNA generation is directly linked with $H P 1 \alpha-V 3$ mRNA generation in a significant amount (Fig. 5b). This cannot rule out the possibility for a stoichiometric effect such that each STET mRNA generated is accompanied with a decreased generation of one $H P 1 \alpha-V 3$ mRNA, but since the total amount of STET mRNA relative to $H P 1 \alpha-V 3$ mRNA is low this will be left undetectable. Finally, we examined how insertion of the $S T E T$ exon in a dual reporter mini-gene under transcriptional control of the hnRNPA1 and CBX5 bi-directional promoter influenced expression. For this, we used the same expression vectors as described in Fig. 1 with the addition of a $1.17 \mathrm{~kb}$ STET exon and flanking sequences insert (Fig. 5c). Transient transfections in MCF7 and MDA-MB231 cells resulted in no significant decrease in the $C B X 5$ transcriptional orientation by inclusion of the STET exon (Fig. 5c). In cell lines with mini-gene integrations by transposition, we also did not detect significant STET exon mediated effects on the $C B X 5$ transcriptional orientation (Fig. 5d). In conclusion, data did not support a model wherein STET exon sequences are mechanistically involved in abolishing the inclusion of downstream consensus HP1 $\alpha$ encoding exons in quantitative amounts to mediate significant down-regulation of $H P 1 \alpha-V 3$ mRNA expression. Instead, the results favour that transcriptional downregulation of the CBX5 gene in MDA-MB-231 cells increases the relative abundance of coupled STET exon alternative splicing and polyadenylation with a resulting increase in STET mRNA expression.

\section{hnRNAP1, HP1a-V3 and STET mRNA expression during breast cancer progression}

We next analysed the relationship between $h n R N P A 1$, $H P 1 \alpha-V 3$ and STET mRNA expression in breast cancer samples to see whether this corresponds to observations from breast cancer cell lines. cDNA was prepared from paired tissue samples from 193 patients with breast cancer $[43,44] .81$ of the patients had metastases in the lymph nodes. From each patient a sample of normal breast tissue and primary breast carcinoma were obtained. From 78 of the patients a sample from the lymph node metastases was obtained. Expression levels for $H P 1 \alpha-V 3, S T E T$, and hnRNPA1 mRNA were measured by RT-qPCR in the normal breast, primary carcinoma samples and lymph node metastases. To acquire a normal distribution, the normalized expression values were log-transformed and all datasets passed the D'AgastinoPearson normality test. Compared to normal breast tissue samples, $H P 1 \alpha-V 3$ mRNA expression was higher in both primary carcinoma samples from patients with lymph node metastasis $(1.75$-fold, $P<0.0001)$ and without lymph metastasis (2.02-fold, $P<0.0001)$ (Fig. 6b). $H P 1 \alpha-V 3$ expression was also higher in lymph node metastases compared to normal breast tissue (1.44-fold, $P<0.001$ ) (Fig. 6b). $H P 1 \alpha-V 3$ expression in the primary carcinoma samples from patients without lymph node metastases was significantly higher than expression in lymph node metastases samples (1.40-fold, $P<0.01$ ) (Fig. 6b). Albeit not statistically significant, there was also a tendency towards down-regulation of $H P 1 \alpha-V 3$ expression in primary carcinoma from patients with metastases compared to lymph nodes metastases (Fig. 6b). For hnRNPA1 mRNA we observed an increased expression between normal breast tissue and primary carcinoma samples from patients without metastasis (1.33-fold, $P<0.01$ ) (Fig. 6a). hnRNPA1 also appeared upregulated in primary carcinoma samples from patients with metastasis, but not significantly (Fig. 6a). No difference in $h n R N P A 1$ mRNA expression was observed between primary carcinoma and lymph node metastases samples (Fig. 6a). These results support the HMEC, MCF7 and MDA-MB-231 cell line results. For the expression ratio between $H P 1 \alpha-V 3$ and $h n R N P A 1$, we observed an increase between normal breast tissue and primary carcinoma samples both from patients without metastasis (1.46-fold, $P<0.0001)$ and patients with metastasis (1.79-fold, $P<0.0001$ ) (Fig. 6c). Also an increase from normal breast tissue to lymph node metastases was significant (1.2-fold, $P<0.05)$ (Fig. 6c). Thereby, the results from the in vivo material were in agreement with the results from cancer cell lines. No significant difference in STET mRNA expression was found between normal tissue and primary carcinoma from patients with or without lymph node metastasis (Fig. 6d). However, expression of STET was in normal breast lower than in lymph node metastases $(0.75$-fold, $P<0.05)$ (Fig. 6d). STET expression was also lower in carcinomas from patients without metastasis $(0.73$-fold, $P<0.05)$ and with metastasis $(0.70$-fold, $P<0.05)$ relative to lymph node metastases (Fig. 6d). The $H P 1 \alpha-V 3$ to STET ratio was significantly higher in primary carcinomas both from patients without metastasis (1.97-fold, $P<0.0001)$ and with metastasis $(1.81$-fold, $P<0.0001)$ relative to normal breast (Fig. 6e). The $H P 1 \alpha-V 3$ to STET ratio was also significantly higher in primary carcinomas both from patients without metastasis (1.76fold, $P<0.0001)$ and with metastasis $(1.61$-fold, $P<0.01)$, compared to lymph node metastases (Fig. 6e). To account for variation in baseline $H P 1 \alpha-V 3$ mRNA expression levels between patients, we performed an alternative data analysis where we normalized the expression of $H P 1 \alpha-V 3$ and STET mRNA to the corresponding 


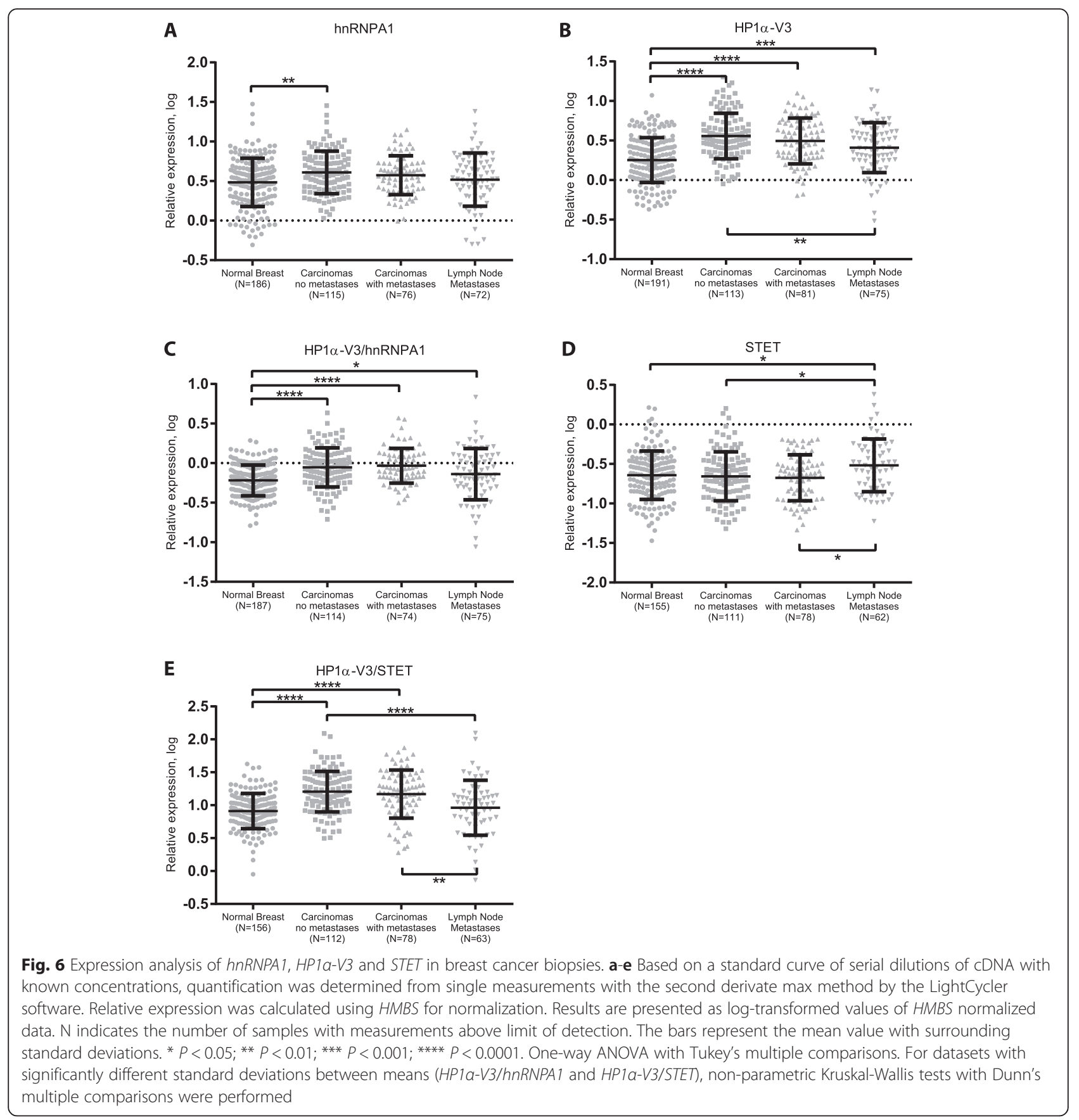

normal breast tissue sample (Additional file 6: Figure S4). For the $H P 1 \alpha-V 3$ to STET mRNA expression ratio, significant differences were observed for both primary carcinoma samples both from patients with metastasis (1.81-fold, $P<0.01$ ) and without metastasis (1.68-fold, $P$ $<0.01$ ) compared to lymph node metastases (Additional file 6: Figure S4). Thus, irrespective of our data analysis method, we identified inverse correlation between $H P 1 \alpha-V 3$ and STET mRNA expression levels for primary breast carcinoma versus lymph node metastases. These findings are in alignment with the data presented for HMEC, MCF7 and MDA-MB-231 cell lines.

\section{Discussion}

HP1 $\alpha$ is over-expressed in several types of cancers and the over-expression is associated with increased cell proliferation most likely through silencing of cell proliferation inhibitors [34]. Moreover, $\mathrm{HP} 1 \alpha$ has a proliferation dependent expression level, which is reduced under transient cell cycle exit [34]. Finally, a decrease in HP1 $\alpha$ 
expression is functionally associated with an increased invasive potential of breast cancer cells most likely due to decreased silencing of pro-invasive genes. The Janusfaced regulation of HP1 $\alpha$ expression during carcinogenesis can be a reflection of the inverse correlation that has been suggested between cancer cell proliferation and invasion [34, 52]. Cancer cell metastasis requires an acquisition of invasive potential and adaptation to a new environment, which can be incompatible with a high proliferation rate. A temporal slowdown of cell proliferation, accompanied by down-regulation of HP1 $\alpha$ expression, can permit the expression of pro-invasive genes, thereby resulting in metastasis [34]. However, the outgrowth of metastases requires cell proliferation and this process can be paramount for the final patient outcome, since high HP1 $\alpha$ expression correlates with earlier diagnosis of metastasis [34]. Because of the inverse correlation between HP1 $\alpha$ expression and the invasive potential of cancer cells, knowledge on the differential regulation of HP1 $\alpha$ expression is an important prospect in fundamental cancer research [34]. In this study, we have shown that the decrease in HP1 $\alpha$ expression in metastatic breast cancer cells involves promoter downstream sequences of the HP1 $\alpha$ encoding $C B X 5$ gene. hnRNPA1 and CBX5 shares a bi-directional promoter structure. Such "head-to-head" gene arrangements are found at a high frequency throughout the human genome with $\sim 11 \%$ of all genes defined as bi-directional promoter genes by being divergently transcribed, and with transcriptional start sites (TSS) less than $1 \mathrm{~kb}$ away from each other [53-55]. Bi-directional arrangements are often evolutionary conserved, indicating functional importance of this specific gene structural modulation [56-58]. In this line, expression of bi-directional promoter genes are more correlated than those of randomly selected and neighboring genes. This is exemplified by gene pairs needed in stoichiometric amounts e.g. histone genes, functioning in the same biological pathway e.g. DNA repair, and co-expressed at specific time points during cycle or in response to induction signals e.g. heat shock [54,59]. Bi-directional promoter sequences share several features separating them from the general nonbi-directional promoters [58]. Bi-directional promoters are more often located within a CpG island (77 \%) compared to non-bi-directional promoters $(38 \%)$ and bi-directional promoters have a GC-content (66\%), which is higher than non-bi-directional promoters (53 \%) [56-58]. Furthermore, the relative presence of canonical TATA box elements is significantly less for bidirectional promoters $(8 \%)$ compared to other promoters $(28 \%)$ [54, 60]. Bi-directional promoters display an enriched occurrence of specific transcription factor binding sites, including GABPA, MYC, E2F, NRF and YY1 [59]. These cis-elements are often functionally shared for both transcriptional directions [54, 61]. The hnRNPA1 and CBX5 bi-directional promoter lacks TATA box elements, contains a CpG island, and includes binding motifs for signature bi-directional promoter transcription factors e.g. YY1, E2F and MYC, and thus is a consensus representative of bi-directional promoters [37, 40, 41, 62, 63]. We identified no significant correlated expression pattern between hnRNPA1 and $C B X 5$ in the NCI-60 cancer cell panel. This is illustrated by the $C B X 5$ down-regulation in metastatic breast cancer cells compared to poorly invasive breast cancer cell lines whereas $h n R N P A 1$ is relatively evenly expressed in both types of cell lines [36, 37, 40, 41]. However, we note that from normal breast epithelial cells to MCF7 cells both hnRNPA1 and CBX5 are up-regulated. The scenario is different for the $C B X 3$ and hnRNPA2B1 bidirectional promoter that results in a highly correlated expression of these two genes in the NCI-60 cancer cell panel including MCF7 and MDA-MB-231 cells. Thus, for $h n R N P A 1$ and CBX5 evolution must have adapted regulatory mechanisms un-coupling the expression of the two genes under certain cellular environments e.g. during breast cancer metastasis. Going from an in vitro breast cancer cell model using HMEC, MCF7 and MDA-MB-231 cells to clinical breast cancer samples, we could largely replicate findings concerning the upregulation of both hnRNPA1 and CBX5 in carcinoma versus normal breast epithelial cells, de-coupling of hnRNAP1 and CBX5 expression in metastatic breast cancer cells, and the relative up-regulation of the STET transcript in metastatic breast cancer cells. This validates that in this case our cell line based model is valuable for investigating in vivo breast cancer progression.

Previous studies have focused on human CBX5 regulation in terms of cis-elements and transcription factor binding to the consensus promoter region upstream and in exon 1. This resulted in the identification of a USF/CMYC recognition site upstream for the $C B X 5$ transcriptional start site to be involved mediating differential expression in invasive versus poorly invasive breast cancer cells [40]. Based on observations in both transient and genome integrated reporter systems, our presented analyses point to importance of also promoter downstream transcriptional regulatory events. We observed that the isolated hnRNPA1 and CBX5 bi-directional promoter shows no significant preference for $C B X 5$ relative to hnRNPA1 down-regulation in MDA-MB-231 cells. One hint of a transcriptional regulatory mechanism for $C B X 5$ beyond promoter mediated initiation comes from a recent study of transcriptional pausing [64]. The majority of human genes are at the promoter proximal region loaded with paused Pol-II poised for release by the positive elongation factor pTEFb into productive elongation. Gdown1 was shown to be a sub-stoichiometric subunit 
of Pol-II complex. Gdown1 inhibits termination of Pol II by TTF2 thereby preventing release of short transcripts and Pol-II dissociation, blocking elongation stimulation by TFIIF and influencing pausing factors NEFL and DSIF. The hnRNPA1 and CBX5 promoters are both associated with Gdown1 and poised Pol-II [64]. Notably, two such Pol-II and Gdown1 peaks are present at $C B X 5$ 50 and 450 bp downstream of the bi-directional promoter [64]. Since binding of Gdown1 to the promoter is linked with efficient transcriptional elongation and promoting stability of the paused Pol-II complex, deficiency in Gdown1 functional association to the bi-directional promoter in MDA-MB-231 cells could be a theoretical possibility. Thus, a skewed expression pattern in favor of hnRNPA1 expression relative to CBX5 expression will be obtainable, given the Gdown 1 effect is directed specifically towards $C B X 5$ in a yet not proven mechanism. This scenario is in line with our previous observation of less abundance of the transcriptional elongation chromatin mark H3K36me3 in MDA-MB-231 cells [37, 65]. Importantly, we observed that throughout the $C B X 5$ gene, with the exception of the STET transcript to be discussed below, lesser amounts of transcripts were present in MDA-MB-231 cells compared to MCF7 cells. We have described that in MDA-MB-231 cells less Pol-II was present at the promoter compared to MCF7 cells [37]. We note that Gdown1 is equally expressed in MCF7 and MDA-MB-231 cells (Additional file 2: Table S2).

Another possibility in breast cancer cells to mechanistically disconnect generation of HP1 $\alpha$ from the functionally shared promoter architecture for $C B X 5$ and hnRNPA1 is the use of downstream alternative promoters producing HP1 $\alpha$ coding transcripts. We identified two such alternative promoters in the $C B X 5$ intron 1 resulting in two additional HP1 $\alpha$ encoding transcripts, $H P 1 \alpha-V 1$ and $H P 1 \alpha-V 2$. Both transcripts contain the entire full-length HP1 $\alpha$ coding region, but with an alternative first exon not included in the canonical $\mathrm{HP} 1 \alpha$ encoding transcript, $H P 1 \alpha-V 3$. However, in the cancer cell lines the quantitative significant production of $\mathrm{HP} 1 \alpha$ was concluded to be restricted to transcripts produced from the bi-directional promoter. In HMEC, MCF7 and MDA-MB-231 cells we observed an inverse expression pattern of $H P 1 \alpha-V 3$ compared to $H P 1 \alpha-V 1$ and $H P 1 \alpha$ $V 2$. This could be a consequence of transcriptional interference where high transcriptional rate dictated from the bi-directional promoter repressed activity of the downstream alternative promoters. It should not be ruled out that the alternative $C B X 5$ promoters e.g. in certain cell or tissue types or during cell cycle or developmental stages, could contribute significantly to HP1 $\alpha$ expression. In line with this, we note that we in HeLa cells observed a significant contribution of theses alternative transcripts to the total content of HP1 $\alpha$ encoding
mRNA. Recently, an alternative downstream promoter for generating HP1 $\alpha$ encoding mRNA was described in mice and the significance can be based upon a high degree of sequence conservation in mammalians of the genomic region corresponding to the alternative promoters [66]. Surprisingly, we observed after TSA treatment of MDA-MB-231 cells a coordinated and strong down-regulation of $H P 1 \alpha-V 3, H P 1 \alpha-V 1, H P 1 \alpha-V 2$, and STET transcripts as well as down-regulation of HP1 $\alpha$ protein expression. hnRNPA1 was also down-regulated but to a lesser extent. In MCF7 cells hnRNPA1 was repressed by TSA in magnitude similar to MDA-MB-231 cells whereas $C B X 5$ transcripts displayed only a minor and non-coordinated response. MDA-MB-231 ChIP experiments showed no TSA induced increase in levels of acetylated histone $\mathrm{H} 3$ at the bi-directional promoter region. Repression of the CBX5-hnRNPA1 locus could be mediated through recruitment of a TSA induced transrepressor. However, we note that the TSA induced decrease of the $C B X 5$ transcripts in MDA-MB-231 cells was more pronounced than could expected for only an effect on transcription given the relative high mRNA stability (Additional file 5: Figure S3 and [37]). This could indicate TSA induced de-stabilization of CBX5 transcripts, similar to e.g. claudin-1 mRNA [67].

Bioinformatics analysis, as well as analysis of the mouse CBX5 gene, revealed presence of several evolutionary conserved regions and transcribed regions in $C B X 5$ intron 1 [66]. Our further investigation of one such region led to the identification of two novel transcripts from CBX5 termed STET1 and STET2. These are transcribed from the same promoter as $H P 1 \alpha-V 3$ mRNA and thereby contain exon 1 which is now spliced to an intron 1 embedded alternative exon located $\sim 5 \mathrm{~kb}$ downstream of the TSS. The alternative STET exon includes a functional pA signal. STET mRNA generation thereby constitute an alternative cleavage and polyadenylation (APA) event and the STET exon E2A classifies as a composite terminal exon. Studies analyzing APA events have mainly been focused on the 3'-UTR, but RNA-sequence analysis have revealed that $20 \%$ of human genes have at least one intronic APA event and that the APA events can be developmental and cell cycle regulated to regulate expression [68-70]. We note that E2F transcription factors were described to enhance alternative intronic polyadenylation in a cell proliferative dependent manner and the presence of a E2F cis-element in the bi-directional promoter could provide a link to STET mRNA generation [71]. Mechanistic selection of STET alternative splicing and polyadenylation is expected in stoichiometric amounts to decrease the generation of $H P 1 \alpha-V 3$ transcripts with $H P 1 \alpha$ encoding potential. Given that STET is relatively more expressed in MDA-MB-231 cells compared to MCF7 cells this 
opens an appealing model for the specific $C B X 5$ relative to hnRNPA1 down-regulation in MDA-MB-231 cells. This will however require that STET mRNA generation in quantitative amounts is comparable with HP1 $\alpha$ encoding mRNA. Since our analyses systematically identified STET mRNA in minor amounts compared to HP1 $\alpha$ encoding mRNA, we have no supportive evidence for such a regulatory model. Furthermore, insertion of the STET composite terminal exon in a mini-gene background had neither in transient nor genome integrated analysis a negative influence for the inclusion of a STET exon downstream located exon. Finally, despite that we find the bi-directional promoter equally transcriptional prone in MCF7 and MDA-MB-231 cells, we also observed less exon 1 included transcripts and less Pol-II, TBP, TFIIB, and TFIIH loading on the canonical CBX5 promoter in MDA-MB-231 cells indicating less transcription [37]. It is important to notice that histone $\mathrm{H} 3$ as well as H3K9ac and H3K4me3 occupancy over the $C B X 5$ promoter was similar in the two cell lines pointing that the chromatin structure per se is not inhibitory in MDA-MB-231 cells [37]. Thereby, the current results could fit a model wherein reduced $C B X 5$ transcriptional quality in metastatic breast cancer cells mediated by downstream elements e.g. through impaired transcriptional re-initiation and elongation, results in relative increased inclusion of the STET composite exon.

History has dictated genes to be perceived as linear entities confined by promoters and terminators that determine where transcription starts and ends. Studies concerning the regulation of HP1 $\alpha$ have hence mainly been restricted to the canonical $C B X 5$ promoter region. However, our presented results for the differentially expressed $C B X 5 \mathrm{mRNA}$ and the constitutively expressed hnRNPA1 mRNA have indicated novel mechanisms associated with regulation of HP1 $\alpha$ expression through sequences located downstream the bi-directional promoter. The present study highlights the need for additional focus on the transcriptional regulatory mechanistic backgrounds for deregulated HP1 $\alpha$ expression under development and metastatic progression of breast cancer.

\section{Conclusion}

In this study, we demonstrate that an hnRNPA1 and $C B X 5$ bi-directional core promoter fragment shows no significant preference for $C B X 5$ relative to $h n R N P A 1$ down-regulation in metastatic MDA-MB-231 cells. Thus, we conclude that the bi-directional promoter region per se is not sufficient to mediate preferential $C B X 5$ down-regulation compared to hnRNPA1 in MDA-MB231 cells versus MCF7 cells, but involve sequences located downstream the canonical $C B X 5$ promoter. Characterization of transcriptional events in the $C B X 5$
$20 \mathrm{~kb}$ long intron 1 revealed existence of several novel CBX5 transcripts. Two of these encoded consensus HP1 $\alpha$ protein but used autonomous promoters located within intron 1 by which HP1 $\alpha$ expression could be decoupled from the bi-directional promoter. However, in breast cancer cell lines a quantitative significant production of HP1 $\alpha$ was concluded to be restricted to transcripts with origin from the bi-directional promoter. In addition, a novel CBX5 transcriptional isoform, STET, was discovered. This transcript includes $C B X 5$ exon 1 and part of intron 1 sequences through alternative splicing and polyadenylation, but lacks inclusion of HP1 $\alpha$ encoding exons. Inverse correlation between STET and HP1 $\alpha$ coding mRNA expression, transcribed from the canonical $C B X 5$ bi-directional promoter was observed in both breast cancer cell lines and samples from breast cancer patients. Mechanistic selection of STET alternative splicing and polyadenylation is expected in stoichiometric amounts to decrease the generation of $C B X 5$ transcripts with $\mathrm{HP} 1 \alpha$ encoding potential. This could thereby comprise a novel mechanism of HP1 $\alpha$ encoding mRNA regulation. However, we systematically identified STET mRNA in minor amounts compared to HP1 $\alpha$ encoding mRNA. Moreover, insertion of the STET composite terminal exon in a mini-gene background had neither in transient nor genome integrated analysis a negative influence for the inclusion of a STET exon downstream located exon. Thus, we have no supportive evidence for such a regulatory model. Therefore, the results more likely reflects a model wherein reduced $C B X 5$ transcriptional quality mediated by promoter downstream mechanisms e.g. through impaired transcriptional re-initiation and elongation, results in relative increased inclusion of the STET composite exon.

\section{Availability of supporting data}

All the supporting data are included as additional files.

\section{Additional files}

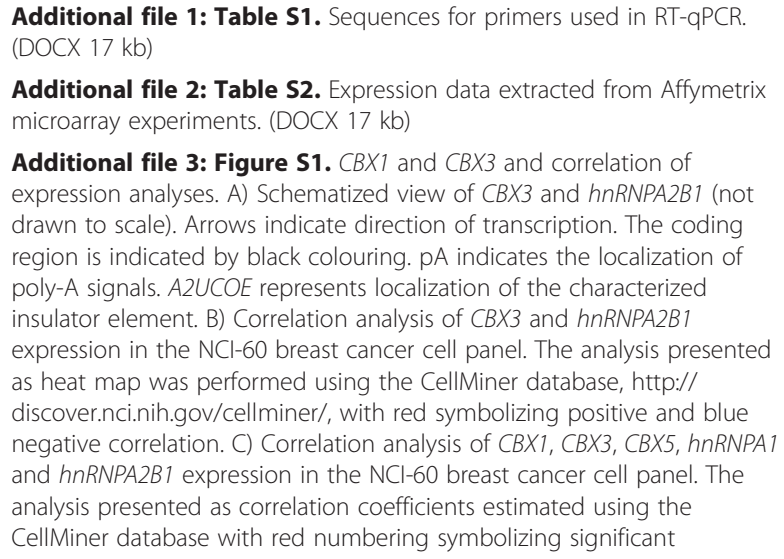

Additional file 2: Table S2. Expression data extracted from Affymetrix microarray experiments. (DOCX $17 \mathrm{~kb}$ )

Additional file 3: Figure S1. $C B X 1$ and $C B X 3$ and correlation of expression analyses. A) Schematized view of CBX3 and hnRNPA2B1 (not drawn to scale). Arrows indicate direction of transcription. The coding region is indicated by black colouring. pA indicates the localization of poly-A signals. A2UCOE represents localization of the characterized insulator element. B) Correlation analysis of CBX3 and hnRNPA2B1 expression in the $\mathrm{NCl}-60$ breast cancer cell panel. The analysis presented as heat map was performed using the CellMiner database, http:// discover.nci.nih.gov/cellminer/, with red symbolizing positive and blue negative correlation. C) Correlation analysis of CBX1, CBX3, CBX5, hnRNPA1 and $h n R N P A 2 B 1$ expression in the $\mathrm{NCl}-60$ breast cancer cell panel. The analysis presented as correlation coefficients estimated using the CellMiner database with red numbering symbolizing significant 
expression correlation. D) Schematized view of $C B X 1$ and neighboring SNX11 (not drawn to scale). Arrows indicate direction of transcription. The coding region is indicated by black coloring. The position of a promoter overlapping CpG island is shown. (PDF $380 \mathrm{~kb}$ )

Additional file 4: Figure S2. TSA effects on $C B X 1, C B X 3$ and $C B X 5$ expression. A) mRNA expression analysis of the $C B X 1, C B X 3$ and $C B X 5$ response towards TSA. Relative expression levels of CBX mRNA in MCF7 and MDA-MB-231 cells after $24 \mathrm{~h}$ treatment with TSA or control DMSO. Relative expression was calculated from RT-qPCR using GAPDH expression for normalization. For all panels, bars represent mean values with standard deviations. B) Immunofluorescence analysis of HP1a (upper panels) or DAPI staining in MDA-MB-231 cells either untreated or TSA treated for $24 \mathrm{~h}$. C) Zooming in on a representative immunofluorescence analysis of HP1a in MDA-MB-231 cells with arrows pointing on heterochromatic spots. (PDF $914 \mathrm{~kb}$ )

Additional file 5: Figure S3. RNA stability analysis of HP1a-V3 and STET. A-B) mRNA decay analysis of HP1a-V3, STET and C-MYC following Actinomycin D treatment in MCF7 (A) and MDA-MB-231 cells (B). Cells were treated with Actinomycin $D$ and harvested at indicated time points. Relative expression was calculated from RT-qPCR using GAPDH expression for normalization. C) Knockdown efficiency of siRNA mediated knockdown of RRP6 and RRP40 mRNA in MCF7 and MDA-MB-231 cells, respectively. Expression of HP1a-V3, STET and amplicon A1 RNA after RRP6 and RRP40 siRNA mediated knockdown in MCF7 and MDA-MB-231 cells, respectively. Relative expression was calculated from RT-qPCR using GAPDH expression for normalization. For all panels, bars represent mean values with standard deviations. (PDF $574 \mathrm{~kb}$ )

Additional file 6: Figure S4. Expression analysis of hnRNPA1, HP1a-V3 and STET in breast cancer biopsies normalized to normal breast biopsies. A-E) Based on a standard curve of serial dilutions of CDNA with known concentrations, quantification was determined from single measurements with the second derivate max method by the LightCycler software. Relative expression was calculated using HMBS for normalization. To correct for diversity of baseline expression between patients, expression of each carcinoma sample was further normalized to the corresponding normal breast tissue sample of that patient. Results are presented as logtransformed values of HMBS and normal breast tissue normalized data. $\mathrm{N}$ indicates the number of samples with measurements above limit of detection. For all panels, bars represent mean values with standard deviations. ${ }^{*} P<0.01$; one-way ANOVA with Tukey's multiple comparison. For datasets with significantly different standard deviations between means non-parametric Kruskal-Wallis test with Dunn's multiple comparison was performed. (PDF $333 \mathrm{~kb}$ )

\section{Abbreviations}

aa: Amino acid; ac: Acetylation; APA: Alternative cleavage and polyadenylation; CBX: Chromo box protein homolog; CD: Chromo domain; ChIP: Chromatin immunoprecipitation; CoTC: Co-transcriptional cleavage; CSD: Chromoshadow domain; EGFP: Enhanced green fluorescent protein; H3: Histone 3; H3K9: Histone H3 lysine position 9; H3K9ac: Histone H3 lysine position 9 acetylation; H3K9me2/3: Histone H3 lysine position 9 di- and trimethylation; HP1: Heterochromatin protein 1; K: Lysine; KAT: Katushka fluorescent protein; me2: Di-methylation; me3: Tri-methylation; ORF: Open reading frame; $\mathrm{PA}$ signal: Polyadenylation signal; PEV: Position effect variegation; Pol-II: RNA polymerase II; RT-qPCR: Reverse transcriptase quantitative PCR; SD: Standard deviation; STET: Skipped terminal exon transcript; TSA: Trichostatin-A; UTR: Untranslated region.

\section{Competing interests}

The authors declare that they have no competing interests.

\section{Authors' contributions}

JVN and ALN designed the experiments. JVN, KRJ, RT, and TD conducted the experiments. AB and BSS collected and prepared the tissue samples from breast cancer patients. JVN and ALN analyzed the data obtained from the experiments. JVN and ALN wrote the manuscript. All authors read and approved the manuscript.

\section{Acknowledgements}

This work was supported by The Lundbeck Foundation, Familien Hede Nielsens Fond, Direktør Jacob Madsen \& Hustru Olga Madsens Fond, Fabrikant Einar Willumsens Mindelegat, Marie og Børge Kroghs Fond, and Fonden til Lægevidenskabens Fremme. We thank Toke Elbæk Linnet and Dennis Bruun Christensen for the scientific contribution to the hereby presented results.

\section{Author details}

${ }^{1}$ Department of Biomedicine, The Bartholin building, Aarhus University, DK-8000 Aarhus C, Denmark. ${ }^{2}$ Department of Clinical-Biochemistry, Aarhus University Hospital, Aarhus, Denmark. ${ }^{3}$ Department of Pathology, Aalborg University Hospital, Aalborg, Denmark.

Received: 1 April 2015 Accepted: 10 January 2016

Published online: 20 January 2016

\section{References}

1. James TC, Elgin SC. Identification of a nonhistone chromosomal protein associated with heterochromatin in Drosophila melanogaster and its gene. Mol Cell Biol. 1986;6(11):3862-72.

2. Singh PB, Miller JR, Pearce J, Kothary R, Burton RD, Paro R, et al. A sequence motif found in a Drosophila heterochromatin protein is conserved in animals and plants. Nucleic Acids Res. 1991;19(4):789-94.

3. Saunders WS, Chue C, Goebl M, Craig C, Clark RF, Powers JA, et al. Molecular cloning of a human homologue of Drosophila heterochromatin protein HP1 using anti-centromere autoantibodies with anti-chromo specificity. J Cell Sci. 1993;104(Pt 2):573-82.

4. Le Douarin B, Nielsen AL, Garnier JM, Ichinose H, Jeanmougin F, Losson R, et al. A possible involvement of TIF1 alpha and TIF1 beta in the epigenetic control of transcription by nuclear receptors. EMBO J. 1996;15(23):6701-15.

5. Nielsen AL, Ortiz JA, You J, Oulad-Abdelghani M, Khechumian R, Gansmuller A, et al. Interaction with members of the heterochromatin protein 1 (HP1) family and histone deacetylation are differentially involved in transcriptional silencing by members of the TIF1 family. EMBO J. 1999:18(22):6385-95.

6. Paro R, Hogness DS. The Polycomb protein shares a homologous domain with a heterochromatin-associated protein of Drosophila. Proc Natl Acad Sci U S A. 1991;88(1):263-7.

7. Aasland R, Stewart AF. The chromo shadow domain, a second chromo domain in heterochromatin-binding protein 1, HP1. Nucleic Acids Res. 1995; 23(16):3168-73.

8. Nielsen AL, Oulad-Abdelghani M, Ortiz JA, Remboutsika E, Chambon P, Losson R. Heterochromatin formation in mammalian cells: interaction between histones and HP1 proteins. Mol Cell. 2001;7(4):729-39.

9. Minc E, Allory Y, Worman HJ, Courvalin JC, Buendia B. Localization and phosphorylation of HP1 proteins during the cell cycle in mammalian cells. Chromosoma. 1999;108(4):220-34.

10. Nielsen AL, Sanchez C, Ichinose $H$, Cervino M, Lerouge T, Chambon $P$, et al. Selective interaction between the chromatin-remodeling factor BRG1 and the heterochromatin-associated protein HP1alpha. EMBO J. 2002;21(21): 5797-806.

11. Lachner $M, O^{\prime}$ Carroll $D$, Rea $S$, Mechtler $K$, Jenuwein T. Methylation of histone H3 lysine 9 creates a binding site for HP1 proteins. Nature. 2001; 410(6824):116-20

12. Nielsen SJ, Schneider R, Bauer UM, Bannister AJ, Morrison A, O'Carroll D, et al. $\mathrm{Rb}$ targets histone $\mathrm{H} 3$ methylation and HP1 to promoters. Nature. 2001; 412(6846):561-5.

13. Daujat S, Zeissler U, Waldmann T, Happel N, Schneider R. HP1 binds specifically to Lys26-methylated histone H1.4, whereas simultaneous Ser27 phosphorylation blocks HP1 binding. J Biol Chem. 2005;280(45):38090-5.

14. Brasher SV, Smith BO, Fogh $\mathrm{RH}$, Nietlispach D, Thiru A, Nielsen PR, et al. The structure of mouse HP1 suggests a unique mode of single peptide recognition by the shadow chromo domain dimer. EMBO J. 2000;19(7): 1587-97.

15. Cowieson NP, Partridge JF, Allshire RC, McLaughlin PJ. Dimerisation of a chromo shadow domain and distinctions from the chromodomain as revealed by structural analysis. Curr Biol. 2000;10(9):517-25.

16. Le Douarin B, You J, Nielsen AL, Chambon P, Losson R. TIF1alpha: a possible link between KRAB zinc finger proteins and nuclear receptors. J Steroid Biochem Mol Biol. 1998;65(1-6):43-50. 
17. Ye Q, Callebaut I, Pezhman A, Courvalin JC, Worman HJ. Domain-specific interactions of human HP1-type chromodomain proteins and inner nuclear membrane protein LBR. J Biol Chem. 1997;272(23):14983-9.

18. Seeler JS, Marchio A, Sitterlin D, Transy C, Dejean A. Interaction of SP100 with HP1 proteins: a link between the promyelocytic leukemia-associated nuclear bodies and the chromatin compartment. Proc Natl Acad Sci U S A. 1998;95(13):7316-21

19. Murzina N, Verreault A, Laue E, Stillman B. Heterochromatin dynamics in mouse cells: interaction between chromatin assembly factor 1 and HP1 proteins. Mol Cell. 1999;4(4):529-40.

20. Vad-Nielsen J, Nielsen AL. Beyond the histone tale: HP1alpha deregulation in breast cancer epigenetics. Cancer Biol Ther. 2015;16(2):189-200.

21. Nozawa RS, Nagao K, Masuda HT, Iwasaki O, Hirota T, Nozaki N, et al. Human POGZ modulates dissociation of HP1alpha from mitotic chromosome arms through Aurora B activation. Nat Cell Biol. 2010;12(7): 719-27.

22. Yamamoto K, Sonoda M. Self-interaction of heterochromatin protein 1 is required for direct binding to histone methyltransferase, SUV39H1. Biochem Biophys Res Commun. 2003;301(2):287-92.

23. Lavigne M, Eskeland R, Azebi S, Saint-Andre V, Jang SM, Batsche E, et al. Interaction of HP1 and Brg1/Brm with the globular domain of histone $\mathrm{H} 3$ is required for HP1-mediated repression. PLoS Genet. 2009;5(12):e1000769.

24. Richart AN, Brunner Cl, Stott K, Murzina NV, Thomas JO. Characterization of chromoshadow domain-mediated binding of heterochromatin protein 1alpha (HP1alpha) to histone H3. J Biol Chem. 2012;287(22):18730-7.

25. Dawson MA, Bannister AJ, Gottgens B, Foster SD, Bartke T, Green AR, et al. JAK2 phosphorylates histone H3Y41 and excludes HP1alpha from chromatin. Nature. 2009;461(7265):819-22.

26. Jang SM, Azebi S, Soubigou G, Muchardt C. DYRK1A phoshorylates histone $\mathrm{H} 3$ to differentially regulate the binding of HP1 isoforms and antagonize HP1-mediated transcriptional repression. EMBO Rep. 2014;15(6):686-94.

27. Maison C, Bailly D, Peters AH, Quivy JP, Roche D, Taddei A, et al. Higherorder structure in pericentric heterochromatin involves a distinct pattern of histone modification and an RNA component. Nat Genet. 2002;30(3):329-34.

28. Muchardt C, Guilleme M, Seeler JS, Trouche D, Dejean A, Yaniv M. Coordinated methyl and RNA binding is required for heterochromatin localization of mammalian HP1alpha. EMBO Rep. 2002;3(10):975-81.

29. Allo M, Buggiano V, Fededa JP, Petrillo E, Schor I, de la Mata M, et al. Control of alternative splicing through siRNA-mediated transcriptional gene silencing. Nat Struct Mol Biol. 2009;16(7):717-24.

30. Ameyar-Zazoua M, Rachez C, Souidi M, Robin P, Fritsch L, Young R, et al. Argonaute proteins couple chromatin silencing to alternative splicing. Nat Struct Mol Biol. 2012;19(10):998-1004.

31. Wallrath LL. Unfolding the mysteries of heterochromatin. Curr Opin Genet Dev. 1998;8(2):147-53.

32. Eissenberg JC, James TC, Foster-Hartnett DM, Hartnett T, Ngan V, Elgin SC. Mutation in a heterochromatin-specific chromosomal protein is associated with suppression of position-effect variegation in Drosophila melanogaster. Proc Natl Acad Sci U S A. 1990;87(24):9923-7.

33. Eissenberg JC, Morris GD, Reuter G, Hartnett T. The heterochromatin-associated protein HP-1 is an essential protein in Drosophila with dosage-dependent effects on position-effect variegation. Genetics. 1992;131(2):345-52.

34. De Koning L, Savignoni A, Boumendil C, Rehman H, Asselain B, Sastre-Garau $X$, et al. Heterochromatin protein 1alpha: a hallmark of cell proliferation relevant to clinical oncology. EMBO Mol Med. 2009;1(3):178-91.

35. Kirschmann DA, Seftor EA, Nieva DR, Mariano EA, Hendrix MJ. Differentially expressed genes associated with the metastatic phenotype in breast cancer. Breast Cancer Res Treat. 1999;55(2):127-36.

36. Kirschmann DA, Lininger RA, Gardner LM, Seftor EA, Odero VA, Ainsztein AM, et al. Down-regulation of HP1Hsalpha expression is associated with the metastatic phenotype in breast cancer. Cancer Res. 2000;60(13):3359-63.

37. Thomsen R, Christensen DB, Rosborg S, Linnet TE, Blechingberg J, Nielsen AL. Analysis of HP1alpha regulation in human breast cancer cells. Mol Carcinog. 2011;50(8):601-13.

38. Norwood LE, Moss TJ, Margaryan NV, Cook SL, Wright L, Seftor EA, et al. A requirement for dimerization of $\mathrm{HP} 1 \mathrm{Hsalpha}$ in suppression of breast cancer invasion. J Biol Chem. 2006;281(27):18668-76.

39. Debies MT, Welch DR. Genetic basis of human breast cancer metastasis. J Mammary Gland Biol Neoplasia. 2001;6(4):441-51.

40. Norwood LE, Grade SK, Cryderman DE, Hines KA, Furiasse N, Toro R, et al. Conserved properties of HP1(Hsalpha). Gene. 2004;336(1):37-46.
41. Lieberthal JG, Kaminsky M, Parkhurst CN, Tanese N. The role of YY1 in reduced HP1alpha gene expression in invasive human breast cancer cells. Breast Cancer Res. 2009;11(3):R42.

42. Bekenstein $\mathrm{U}$, Soreq $\mathrm{H}$. Heterogeneous nuclear ribonucleoprotein A1 in health and neurodegenerative disease: from structural insights to posttranscriptional regulatory roles. Mol Cell Neurosci. 2013;56:436-46.

43. Brügmann A, Jensen V, Garne JP, Nexo E, Sorensen BS. Expression of the Epidermal Growth Factor Receptors and Ligands in Paired Samples of Normal Breast Tissue, Primary Breast Carcinomas and Lymph Node Metastases. Adv Breast Cancer Res. 2014;3:22-37. http://dx.doi.org/10.4236/abcr.2014.32005.

44. Palimaru I, Brugmann A, Wium-Andersen MK, Nexo E, Sorensen BS. Expression of PIK3CA, PTEN mRNA and PIK3CA mutations in primary breast cancer: association with lymph node metastases. SpringerPlus. 2013;2:464.

45. Thomsen R, Solvsten CA, Linnet TE, Blechingberg J, Nielsen AL. Analysis of qPCR data by converting exponentially related $\mathrm{Ct}$ values into linearly related X0 values. J Bioinform Comput Biol. 2010;8(5):885-900.

46. Andersen $\mathrm{CL}$, Jensen $\mathrm{J}$, Orntoft TF. Normalization of real-time quantitative reverse transcription-PCR data: a model-based variance estimation approach to identify genes suited for normalization, applied to bladder and colon cancer data sets. Cancer Res. 2004;64(15):5245-50.

47. Zhou Z, Thomsen R, Kahns S, Nielsen AL. The NSD3L histone methyltransferase regulates cell cycle and cell invasion in breast cancer cells. Biochem Biophys Res Commun. 2010;398(3):565-70.

48. Zhou Z, Kahns S, Nielsen AL. Identification of a novel vimentin promoter and mRNA isoform. Mol Biol Rep. 2009;37(5):2407-13.

49. Antoniou MN, Skipper KA, Anakok O. Optimizing retroviral gene expression for effective therapies. Hum Gene Ther. 2013;24(4):363-74.

50. Nojima T, Dienstbier M, Murphy S, Proudfoot NJ, Dye MJ. Definition of RNA polymerase II CoTC terminator elements in the human genome. Cell Rep. 2013:3(4):1080-92.

51. Hoque M, Ji Z, Zheng D, Luo W, Li W, You B, et al. Analysis of alternative cleavage and polyadenylation by $3^{\prime}$ region extraction and deep sequencing. Nat Methods. 2013;10(2):133-9.

52. Berglund P, Landberg G. Cyclin e overexpression reduces infiltrative growth in breast cancer: yet another link between proliferation control and tumor invasion. Cell Cycle. 2006;5(6):606-9.

53. Adachi N, Lieber MR. Bidirectional gene organization: A common architectural feature of the human genome. Cell. 2002;109(7):807-9.

54. Trinklein ND, Aldred SF, Hartman SJ, Schroeder DI, Otillar RP, Myers RM. An abundance of bidirectional promoters in the human genome. Genome Res. 2004;14(1):62-6.

55. Yang MQ, Koehly LM, Elnitski LL. Comprehensive annotation of bidirectional promoters identifies co-regulation among breast and ovarian cancer genes. PLoS Comput Biol. 2007;3(4):e72.

56. Koyanagi KO, Hagiwara M, Itoh T, Gojobori T, Imanishi T. Comparative genomics of bidirectional gene pairs and its implications for the evolution of a transcriptional regulation system. Gene. 2005;353(2):169-76.

57. Li YY, Yu H, Guo ZM, Guo TQ, Tu K, Li YX. Systematic analysis of head-tohead gene organization: evolutionary conservation and potential biological relevance. PLoS Comput Biol. 2006;2(7):e74.

58. Yang MQ, Taylor J, Elnitski L. Comparative analyses of bidirectional promoters in vertebrates. BMC Bioinformatics. 2008;9 Suppl 6:S9.

59. Lin JM, Collins PJ, Trinklein ND, Fu Y, Xi H, Myers RM, et al. Transcription factor binding and modified histones in human bidirectional promoters. Genome Res. 2007;17(6):818-27.

60. Yang MQ, Elnitski LL. Diversity of core promoter elements comprising human bidirectional promoters. BMC Genomics. 2008;9 Suppl 2:S3.

61. Wakano C, Byun JS, Di LJ, Gardner K. The dual lives of bidirectional promoters. Biochim Biophys Acta. 2012;1819(7):688-93.

62. Weinmann AS, Yan PS, Oberley MJ, Huang TH, Farnham PJ. Isolating human transcription factor targets by coupling chromatin immunoprecipitation and CpG island microarray analysis. Genes Dev. 2002;16(2):235-44.

63. Oberley MJ, Inman DR, Farnham PJ. E2F6 negatively regulates BRCA1 in human cancer cells without methylation of histone $\mathrm{H} 3$ on lysine 9. J Biol Chem. 2003;278(43):42466-76.

64. Cheng B, Li T, Rahl PB, Adamson TE, Loudas NB, Guo J, et al. Functional association of Gdown 1 with RNA polymerase II poised on human genes. Mol Cell. 2012:45(1):38-50.

65. Zhou Z, Kahns S, Nielsen AL: Identification of a novel vimentin promoter and mRNA isoform. Mol Biol Rep 2010;37(5):2407-13. doi: 10.1007/s11033009-9751-8 
66. Thliveris AT, Clipson L, Sommer LL, Schoenike BA, Hasenstein JR, Schlamp $\mathrm{CL}$, et al. Regulated Expression of Chromobox Homolog 5 Revealed in Tumors of Apc(Min) (/+) ROSA11 Gene Trap Mice. G3. 2012;2(5):569-78.

67. Krishnan M, Singh AB, Smith JJ, Sharma A, Chen X, Eschrich S, et al. HDAC inhibitors regulate claudin-1 expression in colon cancer cells through modulation of mRNA stability. Oncogene. 2010;29(2):305-12.

68. Luo W, Ji Z, Pan Z, You B, Hoque M, Li W, et al. The conserved intronic cleavage and polyadenylation site of CstF-77 gene imparts control of $3^{\prime}$ end processing activity through feedback autoregulation and by U1 SnRNP. PLoS Genet. 2013;9(7):e1003613.

69. Shi Y. Alternative polyadenylation: new insights from global analyses. RNA. 2012;18(12):2105-17.

70. Tian B, Pan Z, Lee JY. Widespread mRNA polyadenylation events in introns indicate dynamic interplay between polyadenylation and splicing. Genome Res. 2007;17(2):156-65.

71. Elkon R, Drost J, van Haaften $G$, Jenal M, Schrier M, Oude Vrielink JA, et al. E2F mediates enhanced alternative polyadenylation in proliferation. Genome Biol. 2012;13(7):R59.

Submit your next manuscript to BioMed Central and we will help you at every step:

- We accept pre-submission inquiries

- Our selector tool helps you to find the most relevant journal

- We provide round the clock customer support

- Convenient online submission

- Thorough peer review

- Inclusion in PubMed and all major indexing services

- Maximum visibility for your research

Submit your manuscript at www.biomedcentral.com/submit
Biomed Central 